\title{
Material Design and Development: From Classical Thermodynamics to CALPHAD and ICME Approaches
}

\author{
Alan A. Luo \\ Department of Materials Science \& Engineering \\ Department of Integrated Systems Engineering \\ The Ohio State University, Columbus, OH 43210, USA
}

\begin{abstract}
This paper presents an overview and examples of material design and development using 1) classical thermodynamics; 2) CALPHAD (CALculation of PHAse Diagrams) modeling; and 3) Integrated Computational Materials Engineering (ICME) approaches. Although the examples are given in lightweight aluminum and magnesium alloys for structural applications, the fundamental methodology and modeling principles are applicable to all materials and engineering applications. The examples in this paper have demonstrated the effectiveness and limitations of classical thermodynamics in solving specific problems (such as nucleation during solidification and solid-state precipitation in aluminum alloys). Computational thermodynamics and CALPHAD modeling, when combined with critical experimental validation, have been used to guide the selection and design of new magnesium alloys for elevated-temperature applications. The future of material design and development will be based on a holistic ICME approach. However, key challenges exist in many aspects of ICME framework, such as the lack of diffusion/mobility databases for many materials systems, limitation of current microstructural modeling capability and integration tools for simulation codes of different length scales.
\end{abstract}

Keywords: Materials design; classical thermodynamics; computational thermodynamics; CALPHAD; Integrated Computational Materials Engineering; alloy development

\section{Introduction}

Materials have paced the evolution of technology for millennia. Their importance in the advance of human civilization is apparent in the naming of historical epochs, from the Stone Age through the Bronze and Iron Ages and into the ongoing Silicon Age [1]. In the last few decades, the discovery and development of new materials have gradually migrated from meticulous experimental exploration using "trial-and-error" and "design of experiments" methods to material design approaches based on thermodynamics and kinetics. The traditional experimental methods generally require long development cycles (generally 10-20 years). Recent work using CALPHAD (CALculation of PHAse Diagrams) tools has accelerated the design and development of new alloys [2-7]. This approach has successfully taken new ultrahigh-strength steels to flight qualification [2]. Other successful examples using computation include the development of Ni-based super alloy GTD262 for gas turbine applications at General Electric [4] and Mg-based alloy AE44 for automotive engine cradle applications at General Motors [7].

More recently, the CALPHAD approach has been broadened to a holistic ICME (Integrated Computational Materials Engineering) framework in the design and development of new materials and products. ICME is defined as the integration of materials information, captured in computational tools, with engineering product performance analysis and manufacturing-process simulation [8]. The Materials Genome Initiative (MGI) [9] proposed by the United States 
government and several major National Academy studies [8, 10, 11] have documented the importance of ICME and its substantial economic payoff to the materials and manufacturing industries.

Advanced light metals (aluminum, magnesium and titanium alloys) are increasingly being used in the automotive, aerospace and consumer industries for weight reduction and structural efficiency $[12,13]$. This paper presents several examples of using classical thermodynamics and CALPHAD modeling in the development of new aluminum and magnesium alloys. Furthermore, it will summarize an ongoing effort to establish a scientific foundation of computational thermodynamics and kinetics and an ICME framework for accelerated design and optimization of light alloys.

\section{Classical Thermodynamics Approach}

The classical thermodynamics approach often focuses on an "isolated" specific problem to develop quantitative descriptions to provide critical "insights" in designing a new material or modification of an existing material. The nucleation theories for phase transformations (solidification and solid-state precipitation), based on classical thermodynamics, have been an important foundation for alloy development for decades. This section provides example of using nucleation theories to select micro-alloying elements for enhanced nucleation in aluminum alloys to achieve improved mechanical properties.

\subsection{Classical Nucleation Theory}

The classical theory for nucleation from vapor phase was first developed by Volmer and Weber [14], and Becker and Doring [15]; and then extended by Turnbull and Fisher [16] to describe homogeneous nucleation in a condensed system. According to their classical theory, the homogeneous nucleation rate for a spherical, strain-free nucleus is given by [14]

$$
\dot{N} \propto \exp \left(-\frac{\Delta G^{*}}{k T}\right)
$$

$\Delta G^{*}$ is Gibbs free energy of formation of a spherical, strain-free, critical-sized nucleus given by

$$
\Delta G^{*}=\frac{16 \pi \gamma^{3}}{3\left(\Delta G_{V}\right)^{2}}
$$

where $\gamma$ is the interfacial energy and $\Delta G_{V}$ the volume Gibbs free energy of transformation.

For heterogeneous nucleation, a substrate reduces the surface energy needed to form a nucleus, and thereby decreases the free energy of formation of the critical sized nucleus by a factor that is function of the contact angle $(\theta)$ at the nucleus/substrate interface. The substrate effect is taken into account by modifying $\Delta G^{*}$ for homogeneous nucleation thus,

$$
\Delta G_{\text {het }}^{*}=\frac{16 \pi \gamma^{3} f(\theta)}{3\left(\Delta G_{V}\right)^{2}}
$$


where the function $f(\theta)$ is given by

$$
f(\theta)=\frac{2-3 \cos \theta+\cos ^{3} \theta}{4}
$$

\subsection{Nucleation Entropy Theory}

Although $\Delta G_{V}$ may be formally related to the extensive and partial molar free energies of the solid and liquid solutions [17], this approach for calculating $\Delta G_{V}$ is not feasible for most alloys since the excess free energy data for the solutions are not available. The volume free energy of nucleation may be more usefully, albeit approximately, related to the volume entropy change for the transformation and degree of supercooling $(\Delta T)$, since the entropy change is more easily estimated, and for the special case of regular solutions it can be accurately expressed in terms of the equilibrium solid/liquid relationships as defined by the phase diagram.

For undercooled alloy solution $\Delta G_{V}$ can be approximated by

$$
\Delta G_{V} \simeq-\Delta S_{V} \Delta T
$$

where $\Delta S_{V}$ is the volume entropy change for the transformation for the total system (i.e. matrix and precipitate phases), and has been termed by Youdelis [18] as the "nucleation entropy". Eq. (5) is a good approximation when the supercooling $\Delta T$ is small. For the case of significant $\Delta T$, Youdelis has derived the following equation showing the effect of temperature on $\Delta G$ for pure component phase changes

$$
\Delta G=-\Delta S \Delta T+\int_{T_{e q u}}^{T} \Delta c_{P} d T-T \int_{T_{e q u}}^{T} \frac{\Delta c_{P}}{T} d T
$$

where $T$ is the transformation temperature, $T_{\text {equ }}$ the equilibrium temperature, $\Delta c_{P}$ the specific heat change during the transformation. Since the data for $\Delta c_{P}$ are not available for most alloy systems, Eq. (5) has been used for most the calculations based on the nucleation entropy theory. Substitution of Eq. (5) for $\Delta G_{V}$ into the classical nucleation rate expression gives

$$
\dot{N} \propto \exp \left(-\frac{K 16 \pi \gamma^{3}}{3\left(\Delta S_{V}\right)^{2}(\Delta T)^{2} k T}\right)
$$

where $K$ is a parameter determined by nucleus geometry, contact angle (for heterogeneous nucleation), etc. It is evident from Eq. (7) that the nucleation rate increases exponentially with the square of the nucleation entropy.

Youdelis [18] has derived an expression for the nucleation entropy for the special case of regular solution behavior for binary alloy phases, assuming isothermal, isobaric, constant phasecomposition conditions are maintained during nucleation. The molar entropy of nucleation $\Delta S$ ( $\Delta S=V_{m} \Delta S_{V}$, where $V_{m}$ denotes the molar volume) can be separated into two parts: the entropy change due to the transformation of the pure components ( $\Delta S_{F}$ for freezing), and the change in

the mixing entropy for the solid/liquid system resulting from the formation of the solid phase $\left(\Delta S_{M}\right)$, i.e. 


$$
\Delta S=\Delta S_{F}+\Delta S_{M}
$$

where

and

$$
\Delta S_{F}=x_{1}^{S}\left(S_{1}^{S}-S_{1}^{l}\right)+x_{2}^{S}\left(S_{2}^{S}-S_{2}^{l}\right)
$$

$$
\Delta S_{M}=R\left[x_{1}^{S} \ln \left(\frac{x_{1}^{l}}{x_{1}^{s}}\right)+x_{2}^{S} \ln \left(\frac{x_{2}^{l}}{x_{2}^{s}}\right)\right]
$$

In the above equations, the $x$ 's refer to the mole fractions, the $S$ 's to the molar entropies, the subscripts 1,2 to the components, the superscripts s, 1 to the solid and liquid phases respectively. $\mathrm{R}$ is the universal gas constant.

The extension of Eqs. (9) and (10) to multicomponent systems is straightforward and is obtained by including terms for all components in the system in the equations for the binary system [19], thus

and

$$
\Delta S_{F}=\sum_{r=1}^{n} x_{r}^{S}\left(S_{r}^{S}-S_{r}^{l}\right)
$$

$$
\Delta S_{M}=R \sum_{r=1}^{n} x_{r}^{S} \ln \left(\frac{x_{r}^{l}}{x_{r}^{s}}\right)
$$

where $x_{r}^{S}$ and $x_{r}^{l}$ refer to the mole fractions of the $r$-th component in the solid and liquid phases respectively, and $S_{r}^{S}$ and $S_{r}^{l}$ are the molar entropies of the $r$-th component in the pure solid and liquid states respectively at nucleation temperature.

The application of Eqs. (12) and (13) to simple binary eutectic systems shows that in general $\left|\Delta S_{M}\right|$ increases with increasing separation of solidus and liquidus lines, and for the eutectic system is maximum at the eutectic composition. It follows that the nucleation rate (and thus grain refinement) should increase with solute concentration for a binary eutectic system; and moreover, that the tendency for nucleation and grain refinement should be particularly strong in alloys precipitating primary phases or intermetallic compounds of components present in the alloy in dilute concentration.

The behavior of $\Delta \mathrm{S}_{F}$ and $\Delta S_{M}$ for the multicomponent system is similar to that for the binary system, i.e., both $\Delta \mathrm{S}_{F}$ and $\Delta S_{M}$ are always negative and $\left|\Delta S_{M}\right|$ increases with difference in composition between solid and liquid phases. For the multicomponent system $\left|\Delta S_{M}\right|$ will also increase with the number of components present in the system. This is particularly so for the precipitation of intermetallic compounds or intermediate phases of limited solubility range, when only the principal component (solvent, 1) is concentrated in the liquid phases $\left(x_{1}^{l}>x_{1}^{S}\right)$ and the remaining minor components (solutes, $2,3, \ldots, \mathrm{n})$ are concentrated in the solid phase $\left(x_{r}^{l} \ll x_{r}^{S}\right.$, $\mathrm{r}=2,3, \ldots, \mathrm{n}$ ), so that only the first term in Eq. (13) is positive (decreasing $\left|\Delta S_{M}\right|$ ), while the remaining terms are negative. In general, since a redistribution of all components necessarily occurs during the nucleation of the primary phase or intermetallic compound in the liquid alloys, it follows that the nucleation entropy and corresponding nucleation rate (other factors being equal) increase with the number of components comprising the alloy system and results in an increased refinement of the solidification structure. 
In the precipitation of intermetallic compounds, or phases of limited solubility in general, the regular solution constraint in the above analyses is removed by combining appropriate reactions, including the compound formation reaction for which the formation entropy is known, to give the entropy for nucleation of the real phase [19].

\subsubsection{Applications in Refinement of Solidification Structure}

The nucleation entropy theory was first applied by Youdelis and coworkers [19-21] to interpret the enhanced grain refinement of Al-Ti alloys through third element additions. It was found that the additions of small amounts of $\mathrm{Si}$ [19] and $\mathrm{Be}$ [20] greatly enhanced grain refinement of $\mathrm{Al}$ by Ti. It was shown that the Si-enhanced grain refinement in Al-Ti alloy is associated with incorporation of up to 15 at $\% \mathrm{Si}$ in the peritectic compound, to give a ternary compound with the approximate stoichiometry of $\mathrm{TiAl}_{2.4} \mathrm{Si}_{0.6}$ [22]. The incorporation of $\mathrm{Si}$ in $\mathrm{TiAl}_{3}$ by $\mathrm{Al}$ replacement (also reported by Raman and Schubert [23]), gives a significantly higher nucleation entropy and nucleation rate for the peritectic compound. Although the peritectic reaction is generally accepted to be a principal factor in the grain refinement of $\mathrm{Al}$ by $\mathrm{Ti}$ [24], it is a secondary stage and first requires the nucleation of the primary $\mathrm{TiAl}_{3}$ crystals. The higher nucleation entropy and nucleation rate for $\mathrm{TiAl}_{2.4} \mathrm{Si}_{0.6}$ vs. $\mathrm{TiAl}_{3}$ will correspondingly result in a finer grain size for the solidification structure. In a similar study of Al-Ti-Be system, Youdelis and Yang [20] have shown that the substantial increase in the nucleation entropy for the ternary compound $\mathrm{TiAl}_{2.30} \mathrm{Be}_{0.85} \mathrm{vs}$. $\mathrm{TiAl}_{3}$ is in qualitative agreement with the observed Be-enhanced in grain refinement of the Al-Ti alloys.

The nucleation entropy theory was also used to account for the carbide refinement in the solidification structure of Co-base [25] and Ni-base [26] superalloys containing $\mathrm{Ta}$ and $\mathrm{Nb}$. The primary carbides in Co-base alloy (HS21) were determined to be $\mathrm{M}_{23} \mathrm{C}_{6}$ type having the approximate stoichiometric formula $\left(\mathrm{Cr}_{0.77} \mathrm{Co}_{0.15} \mathrm{Mo}_{0.08}\right)_{23} \mathrm{C}_{6}$ [26]. Increasing $\mathrm{Ta}$ or $\mathrm{Nb}$ content in the alloy progressively transformed the carbides to $\mathrm{MC}$ type, and for $\mathrm{Ta}$ and $\mathrm{Nb}$ contents exceeding $\sim 1 \%$, the transformation to fine and numerous $\mathrm{TaC}$ or $\mathrm{NbC}$ carbides was essentially complete. The refinement of primary carbide particles in HS-alloys containing $\mathrm{Ta}$ and $\mathrm{Nb}$ is in agreement with the higher calculated nucleation entropies and rates for $\mathrm{MC}$ vs. the $\mathrm{M}_{23} \mathrm{C}_{6}$ type carbides. In the Ni-base superalloy (713C), the primary carbides were determined to be MC type having the approximate composition $\left(\mathrm{Nb}_{0.77} \mathrm{Ti}_{0.23}\right) \mathrm{C}$ [26]. The addition of $\mathrm{Ta}$ or $\mathrm{Nb}$ to the alloy resulted in the incorporation of $\mathrm{Ta}$ or $\mathrm{Nb}$ into the carbides mostly at the expense of $\mathrm{Ti}$, but the carbide type was not changed. No significant refinement of carbides occurred on $\mathrm{Ta}$ and $\mathrm{Nb}$ additions to 713C alloy, which is in agreement with the absence of any significant differences in the nucleation entropies.

\subsubsection{Applications in Precipitation in Aluminum Alloys}

After the considerable success in the solidification structure refinement, the nucleation entropy theory was extended to include precipitation reactions in solid state, and was first applied to interpret the accelerated age-hardening and precipitation in $\mathrm{Al}-\mathrm{Cu}$ alloys containing small amounts of $\mathrm{Be}$ [27]. 
The procedure used to calculate the nucleation entropy for precipitation in solid alloys is similar to that for primary phase nucleation in liquid alloys, except that the solidification reaction must be replaced by the appropriate solid phase transformation, and the corresponding entropy change calculated or estimated [28]. For $\mathrm{Al}-3 \mathrm{Cu}-0.1 \mathrm{Be}$ alloy, the results of EDS and metallographic analysis show that the bet $\theta\left(\mathrm{CuAl}_{2}\right)$ phase dissolves up to $1.7 \% \mathrm{Be}$ to form the compound with approximate stoichiometric formula $\mathrm{CuAl}_{1.9} \mathrm{Be}_{0.1}$ [29]. Compared with $\theta^{\prime}$ and $\theta$ precipitation in $\mathrm{Al}-3 \mathrm{Cu}$ alloy, the higher calculated nucleation entropy and rate for the $\mathrm{Al}-3 \mathrm{Cu}-0.1 \mathrm{Be}$ alloy is consistent with the higher nuclei density dependent " $k$ " parameter of the Avrami equation (for describing the transformation kinetics) obtained for the $\mathrm{CuAl}_{1.9} \mathrm{Be}_{0.1}$, the higher initial densities of $\theta$ particles, and the faster $\theta^{\prime} \rightarrow \theta$ transition in the ternary alloy [30].

Similar studies were carried out on the effects of Be microalloying on Al-0.75Mg-0.5Si alloy [31], and $\mathrm{Al}-2.5 \mathrm{Cu}-1.2 \mathrm{Mg}$ alloy [32] which is the base alloy for several commercial agehardening $\mathrm{Al}$ alloys of the $2 \mathrm{xxx}$ series. The significant improvement in the age-hardening behavior of the alloys is associated with the increase in nucleation entropies and rates for the active precipitates by incorporation of $\mathrm{Be}, \beta^{\prime}\left(\mathrm{Mg}_{2} \mathrm{Si}\right)$ for $\mathrm{Al}-0.75 \mathrm{Mg}-0.5 \mathrm{Si}$ alloy, and $\mathrm{S}^{\prime}$ $\left(\mathrm{Al}_{2} \mathrm{CuMg}\right)$ for the $\mathrm{Al}-2.5 \mathrm{Cu}-1.2 \mathrm{Mg}$ alloy.

\subsection{Strain Energy in Solid State Transformations}

Eq. (7) is applicable to liquid $\rightarrow$ solid transformation (solidification) or other phase changes in which strain energy is negligible. Transformations in solid state (e.g., precipitation), however, are usually accompanied by volume changes that create elastic strain, which must be taken into account in calculating the free energy of formation of a critical-sized nucleus $\left(\Delta G^{*}\right)$. Two general cases must be considered: (1) incoherent nucleation where there is no lattice continuity between the precipitate and matrix, and the strain is hydrostatic in character; and (2) coherent nucleation where the lattice of the precipitate and surrounding matrix are constrained to match, and the strain is determined by the degree of mismatch of the lattices.

The spherical form of embryo is not the lowest energy configuration when strain becomes significant, and the general form of the free energy of formation of an embryo now includes the strain energy per unit volume of precipitate, $W$, i.e.

$$
\Delta G=\left(\Delta G_{V}+W\right) V+\gamma A
$$

where $V$ and $A$ are the volume and surface area of the embryo, respectively. Since $W$ is always positive, it is evident that strain energy increases the critical size for the nucleus, and correspondingly decreases the nucleation rate.

\subsubsection{Incoherent Precipitate}

The problem of strain energy (hydrostatic) arising from incoherent precipitation has been treated by Nabarro [33]. Assuming that all strains are stored in the matrix and that the matrix is 
elastically isotropic, the strain energy per unit volume of oblate and prolate spheroidal particles (with semi axes $r$ and $c$ ) formed is given by

$$
W=\frac{2}{3} \mu_{m}\left(\frac{\Delta V}{V}\right)^{2} f\left(\frac{c}{r}\right)
$$

where $\Delta V / V$ is the fractional volume change in the matrix accompanying the transformation and $\mu_{m}$ the shear modulus of the matrix. The particle shape factor function, $f(c / r)$, has the following values: 1 for a sphere $(c / r=1), 3 / 4$ for a $\operatorname{rod}(c / r \gg 1)$, and 3 for a disk $(c / r \ll 1)$. Thus the strain energy is minimum when the precipitate is in the form of a disk or thin plate and becomes zero as $c / r$ approaches zero.

\subsubsection{Coherent Precipitate}

Eshelby [34] has given a general treatment of the elastic strain energy associated with an ellipsoidal coherent precipitate in an isotropic matrix. Lee et al [35] later extended Eshelby's treatment to the more general case (anisotropic, inhomogeneous) of a coherent ellipsoidal nucleus, and incorporated the energy into the $\Delta G^{*}$ calculation, which is expressed as

$$
\Delta G^{*}=\frac{\pi \gamma^{3}[2+g(\beta)]^{3}}{12 \beta^{2}\left(\Delta G_{V}+W\right)^{2}}
$$

where $\beta=c / r$, and $c=$ length, $r=$ radius of particles, $g(\beta)$ is a particle shape function which is given by

$$
\begin{array}{ll}
g(\beta)=\frac{2 \beta^{2}}{\sqrt{1-\beta^{2}}} \tanh ^{-1}\left(\sqrt{1-\beta^{2}}\right) & (\text { when } \beta<1) \\
g(\beta)=2 & (\text { when } \beta=1) \\
g(\beta)=\frac{2 \beta^{2}}{\sqrt{1-\beta^{-2}}} \sin ^{-1}\left(\sqrt{1-\beta^{-2}}\right) & (\text { when } \beta>1)
\end{array}
$$

\subsection{Al-Li-Cu-Mg Alloy Development}

The Al-Li based alloys offer substantial weight savings in aerospace applications by virtue of their reduced density and increased elastic modulus compared with conventional aluminum alloys [36]. The increased strength of $\mathrm{A} 1-\mathrm{Li}$ alloys is attributed to precipitation of $\delta^{\prime}\left(\mathrm{A} 1_{3} \mathrm{Li}\right)$; however, $\delta^{\prime}$ precipitation also lowers ductility by strain localization and precipitate free zone (PFZ) formation. Subsequent development on A1-Li alloys has concentrated on improving ductility and toughness in quaternary $\mathrm{A} 1-\mathrm{Li}-\mathrm{Cu}-\mathrm{Mg}$ alloys (8090 type) in which $\delta$ ' precipitation is supplemented by the formation of $\mathrm{S}^{\prime}\left(\mathrm{A}_{2} \mathrm{CuMg}\right)$ [37]. The presence of a second precipitating phase can alter the deformation mode. In the case of 8090 alloy containing $\mathrm{S}^{\prime}$ phase, extensive cross slip occurs to give irregular slip lines, indicating $S^{\prime}$ phase is not sheared by glissile dislocations [37]. Also, precipitation of $S^{\prime}$ does not result in PFZs along low-angle grain boundaries. However, $S^{\prime}$ nucleate heterogeneously on dislocations and other defect sites and, hence, the practice of prior-aging deformation (3 to 5\% stretch) to ensure widespread nucleation in the matrix [38]. The prior-aging deformation step is not feasible for many alloy products, so the enhancement of $S^{\prime}$ nucleation by other means must be explored. 
The selection of microalloying elements to stimulate $S^{\prime}$ nucleation was based on two principal factors: the potential for microalloying elements to concentrate in the precipitating phase and/or to significantly restrict the solubility of the precipitate components in the matrix. Both factors increase the entropy and corresponding nucleation rate of the precipitating phase. This section presents the calculations of nucleation entropy and rates of $\mathrm{S}^{\prime}$ phase precipitation and related experimental investigation in a 8090 alloy (Al-2.5Li-1Cu-0.8Mg) microalloyed with $0.6 \mathrm{~V}$ and $0.15 \mathrm{Be}[38]$.

\subsubsection{Calculation of Nucleation Entropy}

It has been experimentally determined that about 0.2 at $\% \mathrm{~V}$ [39] and about 2.5 at $\%$ Be [32] can be incorporated into $\mathrm{S}$ phase, forming $\mathrm{Al}_{1.99} \mathrm{~V}_{0.01} \mathrm{CuMg}$ and $\mathrm{Al}_{1.9} \mathrm{Be}_{0.1} \mathrm{CuMg}$, respectively. To calculate the nucleation entropy for the $\mathrm{S}$ phase, and the corresponding changes due to $\mathrm{V}$ and $\mathrm{Be}$ incorporations, requires the formation entropy $\Delta \mathrm{S}_{\mathrm{f}}\left(\mathrm{Al}_{2} \mathrm{CuMg}\right)$ for the compound, which is not available. Moreover, a calculation of the relative nucleation rates for the corresponding $S$ ' phases requires the interfacial energy $\gamma_{\mathrm{s}^{\prime} / \mathrm{Al}(\alpha)}$, which is also not known. Nevertheless, a useful order-ofmagnitude calculation of the relative nucleation rates can be obtained, since a formation entropy and interfacial energy can be estimated, and which (more importantly) can be assumed to be unchanged by the incorporation of the small amount of $\mathrm{V}$ and Be into the $\mathrm{S}$ phase structure [39].

The nucleation entropy for the $S^{\prime}$ phase is calculated for three cases:

(1) the nucleation of $\mathrm{Al}_{2} \mathrm{CuMg}$ in the base alloy 8090;

(2) nucleation of $\mathrm{Al}_{1.99} \mathrm{~V}_{0.01} \mathrm{CuMg}$, corresponding to $\sim 0.2$ at\% $\mathrm{V}$ incorporation into $\mathrm{S}$ phase, in $60 \mathrm{~V}$ alloy; and

(3) nucleation of $\mathrm{Al}_{1.9} \mathrm{Be}_{0.1} \mathrm{CuMg}$, corresponding to 2.5 at\% Be incorporation into $\mathrm{S}$ phase, in $15 \mathrm{Be}$ alloy

For the purpose of the calculations, the $\mathrm{V}$ and Be contents in the supersaturated $\mathrm{Al}(\alpha)$, solution, will be taken as the maximum solubilities for the ternary Al-V and Al-Be phase diagrams at 590 ${ }^{\circ} \mathrm{C}$, i.e. 0.1 at $\% \mathrm{~V} \mathrm{[40]} \mathrm{and} 0.1$ at $\%$ Be [41], respectively. The solvus temperature for 8090 alloy can be estimated by using the experimental temperature-composition formula provided by Dorward [42]

$$
T(\text { solvus })=284+57.0(\% L i)+34.6(\% C u)+36.5(\% M g)
$$

which for the concentration of $\mathrm{Li}$ (2.47), $\mathrm{Cu}$ (1.24), and $\mathrm{Mg}(0.77)$ in 8090 alloy gives $520{ }^{\circ} \mathrm{C}$, to give a supercooling $(\Delta T)$ of $330 \mathrm{~K}$ for the aging temperature of $190{ }^{\circ} \mathrm{C}$. In this case, the formation entropy for $\mathrm{S}$ phase is the principal unknown; however, as shown in other similar calculations, the formation entropy will not significantly change by the incorporation of $\mathrm{V}$ or $\mathrm{Be}$, and as a result the formation entropy is not the important factor that mixing entropy is in determining the effect of $\mathrm{V}$ or Be incorporation [20]. For the purpose of this calculation, the formation entropy of $25 \mathrm{~J} / \mathrm{K} \cdot \mathrm{mol}$ will be used, which is in the range for other Al intermetallic compounds (e.g. 26.57 J/K.mol for $\mathrm{TiAl}_{3}$ at $463 \mathrm{~K}[43]$ ). 
Tables 1-3 give the appropriate reaction sequences required for removing the regular solution constraint on formation of the phases. The procedure is similar to that used in calculating the nucleation entropy for $\mathrm{TiAl}_{3}$ (and $\mathrm{TiAl}_{2.4} \mathrm{Si}_{0.6}$ ) in $\mathrm{Al}-\mathrm{Ti}$ and $\mathrm{Al}-\mathrm{Ti}-\mathrm{Si}$ alloys [19]. The concentrations in Tables 1-3 are all in atomic percent.

Reaction (1a) in Table 1 is for the (reverse) formation of 1 mole (4 g-atom) of the regular solid solution alloy $\mathrm{Al}-25 \% \mathrm{Cu}-25 \% \mathrm{Mg}$ alloy, for which the mixing entropy $(-34.47 \mathrm{~J} / / \mathrm{K} \cdot \mathrm{mol})$ is calculated using equation

$$
\Delta S^{r e g}=-R\left[x_{A l} \ln x_{A l}+x_{C u} \ln x_{C u}+x_{M g} \ln x_{M g}\right]
$$

Reaction (2a) is the formation of 1 mole of $\mathrm{Al}_{2} \mathrm{CuMg}$, for which the formation entropy of 25.00 $\mathrm{J} / \mathrm{K} \cdot \mathrm{mol}$ is assumed. Reaction (3a) is the nucleation reaction by which 1 mole of regular solid solution of $\mathrm{Al}-25 \% \mathrm{Cu}-25 \% \mathrm{Mg}$ is formed or precipitated from an infinite $(\infty)$ amount of regular solid solution of $\mathrm{Al}-9.1 \% \mathrm{Li}-0.5 \% \mathrm{Cu}-0.8 \% \mathrm{Mg}$, which is the composition of $\mathrm{Al}(\alpha)$ for the base alloy 8090, and assumed to be the composition at the solution treatment temperature for the alloy $\left(590{ }^{\circ} \mathrm{C}\right)$. The entropy for reaction (3a) is calculated using Eq. (13), except that the liquid phase is now replaced by the supersaturated $\alpha$-Al solid solution to give

$$
\Delta S_{M}=R\left[x_{A l}^{s^{\prime}} \ln \left(x_{A l}^{\alpha} / x_{A l}^{s^{\prime}}\right)+x_{C u}^{s^{\prime}} \ln \left(x_{C u}^{\alpha} / x_{C u}^{s^{\prime}}\right)+x_{M g}^{s^{\prime}} \ln \left(x_{M g}^{\alpha} / x_{M g}^{s^{\prime}}\right)\right]
$$

The reference of the regular solid solutions in (1a) and (3a) to the fcc structures for $\mathrm{Al}$ and $\mathrm{Cu}$, and hcp structure for $\mathrm{Mg}$ removes the transformation entropy from the calculation. Reaction (4a) is obtained by adding reaction (1a) to (3a) which gives the nucleation reaction and corresponding nucleation entropy $(-61.18 \mathrm{~J} / \mathrm{K} \cdot \mathrm{mol})$ for the precipitation of one mole of real $\mathrm{Al}_{2} \mathrm{CuMg}$ from a regular behaving supersaturated solid solution of 8090 alloy at the aging treatment temperature of $463 \mathrm{~K}$. The determination of the nucleation entropy of $\mathrm{Al}_{2} \mathrm{CuMg}$ from the real solid alloy requires appropriate thermodynamic information for the latter, which is not available. However, since the difference in molar entropies of mixing for regular and real solutions is small for dilute alloys (both converge to become zero at infinite dilution), the difference in the molar entropy for nucleation of $\mathrm{Al}_{2} \mathrm{CuMg}$ in real vs. regular solution will likewise be small, and for the $\mathrm{Cu}$ and $\mathrm{Mg}$ concentrations in the present alloy $\left(x_{C u}=0.005, x_{M g}=0.008\right)$ negligible.

The molar nucleation entropies for $\mathrm{Al}_{1.99} \mathrm{~V}_{0.01} \mathrm{CuMg}$ and $\mathrm{Al}_{1.9} \mathrm{Be}_{0.1} \mathrm{CuMg}$ are calculated as for $\mathrm{Al}_{2} \mathrm{CuMg}$, with the additional approximation that $\mathrm{V}$ and $\mathrm{Be}$ in $\mathrm{S}$ phase lattice do not significantly change the formation entropy. The basis for this assumption is the structural similarity of $\mathrm{Al}_{2} \mathrm{CuMg}, \mathrm{Al}_{1.99} \mathrm{~V}_{0.01} \mathrm{CuMg}$ and $\mathrm{Al}_{1.9} \mathrm{Be}_{0.1} \mathrm{CuMg}$. The principal factors determining the entropy of a phase are structure and composition, which determine the bond energy. The structure is the principal factor determining bond energy, which is not changed, and the composition difference is small, and assumed negligible in comparison. It is noted that the approximately $2 \%$ and $6 \%$ increases (in magnitude) in the absolute molar nucleation entropy derives mostly from the $\mathrm{V}$ and Be contributions, respectively, to the mixing entropy (c.f. reactions (4a), (4b) and (4c)), which are not significantly altered by errors introduced in the above approximation.

It should be pointed out that the above nucleation entropy calculations were based on the assumption of regular solutions, hence, the absolute entropy values are less relevant to the phase transformations. Nonetheless, as shown in the subsequent sections, the calculations of relative 
nucleation rates of precipitation in various alloys will highlight the effects of microalloying on the precipitation reactions (Table 4). Therefore, the regular solution assumption is less critical in this type of calculations where the relative entropy differences for different alloys will not be affected by the absolute values used calculated in Tables 1-3.

Table 1. Reaction sequence for calculating molar entropy of nucleation of $\mathrm{Al}_{2} \mathrm{CuMg}$ from 8090 alloy at $190{ }^{\circ} \mathrm{C}$

\begin{tabular}{|c|c|c|}
\hline & & $\mathrm{S}, \mathrm{J} / \mathrm{K} \cdot \mathrm{mol}$ \\
\hline (1a) & $4(\mathrm{Al}-25 \% \mathrm{Cu}-25 \% \mathrm{Mg})^{\mathrm{reg}}(\mathrm{s})=2 \mathrm{Al}(\mathrm{s})+\mathrm{Cu}(\mathrm{s})+\mathrm{Mg}(\mathrm{s})$ & -34.47 \\
\hline $\begin{array}{l}+ \\
(2 a)\end{array}$ & $2 \mathrm{Al}(\mathrm{s})+\mathrm{Cu}(\mathrm{s})+\mathrm{Mg}(\mathrm{s})=\mathrm{Al}_{2} \mathrm{CuMg}(\mathrm{s})$ & +25.00 \\
\hline $\begin{array}{l}+ \\
(3 a)\end{array}$ & $\begin{aligned} \infty(\mathrm{Al}-9.1 \% \mathrm{Li}-0.5 \% \mathrm{Cu}-0.8 \% \mathrm{Mg})^{\mathrm{reg}}(\mathrm{s})= & 4(\mathrm{Al}-25 \% \mathrm{Cu}-25 \% \mathrm{Mg})^{\mathrm{reg}}(\mathrm{s}) \\
& +\infty(\mathrm{Al}-9.1 \% \mathrm{Li}-0.5 \% \mathrm{Cu}-0.8 \% \mathrm{Mg})^{\mathrm{reg}}(\mathrm{s})\end{aligned}$ & -51.71 \\
\hline (4a) & $\begin{aligned} \infty(\mathrm{Al}-9.1 \% \mathrm{Li}-0.5 \% \mathrm{Cu}-0.8 \% \mathrm{Mg})^{\mathrm{reg}}(\mathrm{s})= & \mathrm{Al}_{2} \mathrm{CuMg}(\mathrm{s}) \\
& +\infty(\mathrm{Al}-9.1 \% \mathrm{Li}-0.5 \% \mathrm{Cu}-0.8 \% \mathrm{Mg})^{\mathrm{reg}}(\mathrm{s})\end{aligned}$ & -61.18 \\
\hline
\end{tabular}

Table 2. Reaction sequence for calculating molar entropy of nucleation of $\mathrm{Al}_{1.99} \mathrm{~V}_{0.01} \mathrm{CuMg}$ from $60 \mathrm{~V}$ alloy at $190{ }^{\circ} \mathrm{C}$

\begin{tabular}{ccc} 
& $\mathrm{S}, \mathrm{J} / \mathrm{K} \cdot \mathrm{mol}$ \\
\hline$(1 \mathrm{~b})$ & $4(\mathrm{Al}-25 \% \mathrm{Cu}-25 \% \mathrm{Mg}-0.2 \% \mathrm{~V})^{\mathrm{reg}}(\mathrm{s})=1.99 \mathrm{Al}(\mathrm{s})+\mathrm{Cu}(\mathrm{s})+\mathrm{Mg}(\mathrm{s})+0.01 \mathrm{~V}(\mathrm{~s})$ & -35.04 \\
+ & & +25.00 \\
$(2 \mathrm{~b})$ & $1.99 \mathrm{Al}(\mathrm{s})+\mathrm{Cu}(\mathrm{s})+\mathrm{Mg}(\mathrm{s})+0.01 \mathrm{~V}(\mathrm{~s})=\mathrm{Al}_{1.99} \mathrm{~V}_{0.01} \mathrm{CuMg}(\mathrm{s})$ & \\
+ & & -52.42 \\
$(3 \mathrm{~b})$ & $\infty(\mathrm{Al}-8.6 \% \mathrm{Li}-0.5 \% \mathrm{Cu}-0.7 \% \mathrm{Mg}-0.1 \% \mathrm{~V})^{\mathrm{reg}}(\mathrm{s})=4(\mathrm{Al}-25 \% \mathrm{Cu}-25 \% \mathrm{Mg}-0.2 \% \mathrm{~V})^{\mathrm{reg}}(\mathrm{s})$ & $+\infty(\mathrm{Al}-8.6 \% \mathrm{Li}-0.5 \% \mathrm{Cu}-0.7 \% \mathrm{Mg}-0.1 \% \mathrm{~V})^{\mathrm{reg}}(\mathrm{s})$ \\
\hline & $+\infty(\mathrm{Al}-8.6 \% \mathrm{Li}-0.5 \% \mathrm{Cu}-0.7 \% \mathrm{Mg}-0.1 \% \mathrm{~V})^{\mathrm{reg}}(\mathrm{s})=\mathrm{Al}_{1.99} \mathrm{~V}_{0.01} \mathrm{CuMg}(\mathrm{s})$ & -62.46 \\
\hline & $+\infty(\mathrm{Al}-8.6 \% \mathrm{Li}-0.5 \% \mathrm{Cu}-0.7 \% \mathrm{Mg}-0.1 \% \mathrm{~V})^{\mathrm{reg}}(\mathrm{s})$ & \\
\hline
\end{tabular}

Table 3. Reaction sequence for calculating molar entropy of nucleation of $\mathrm{Al}_{1.9} \mathrm{Be}_{0.1} \mathrm{CuMg}$ from 15 Be alloy at $190{ }^{\circ} \mathrm{C}$

\begin{tabular}{|c|c|c|}
\hline & &, $\mathrm{J} / \mathrm{K}$ \\
\hline $\begin{array}{l}(1 \mathrm{c}) \\
+\end{array}$ & $4(\mathrm{Al}-25 \% \mathrm{Cu}-25 \% \mathrm{Mg}-2.5 \% \mathrm{Be})^{\mathrm{reg}}(\mathrm{s})=1.9 \mathrm{Al}(\mathrm{s})+\mathrm{Cu}(\mathrm{s})+\mathrm{Mg}(\mathrm{s})+0.1 \mathrm{Be}(\mathrm{s})$ & -37.87 \\
\hline $\begin{array}{l}(2 \mathrm{c}) \\
+\end{array}$ & $1.9 \mathrm{Al}(\mathrm{s})+\mathrm{Cu}(\mathrm{s})+\mathrm{Mg}(\mathrm{s})+0.1 \mathrm{Be}(\mathrm{s})=\mathrm{Al}_{1.9} \mathrm{Be}_{0.1} \mathrm{CuMg}(\mathrm{s})$ & +25.00 \\
\hline$(3 c)$ & $\begin{array}{r}\infty(\mathrm{Al}-8.8 \% \mathrm{Li}-0.5 \% \mathrm{Cu}-0.8 \% \mathrm{Mg}-0.1 \% \mathrm{Be})^{\mathrm{reg}}(\mathrm{s})=4(\mathrm{Al}-25 \% \mathrm{Cu}-25 \% \mathrm{Mg}-2.5 \% \mathrm{Be})^{\mathrm{reg}}(\mathrm{s}) \\
+\infty(\mathrm{Al}-8.8 \% \mathrm{Li}-0.5 \% \mathrm{Cu}-0.8 \% \mathrm{Mg}-0.1 \% \mathrm{Be})^{\mathrm{reg}}(\mathrm{s})\end{array}$ & -52.63 \\
\hline$(4 c)$ & $\begin{array}{l}\infty(\mathrm{Al}-8.8 \% \mathrm{Li}-0.5 \% \mathrm{Cu}-0.8 \% \mathrm{Mg}-0.1 \% \mathrm{Be})^{\mathrm{reg}}(\mathrm{s})=\mathrm{Al}_{1.9} \mathrm{Be}_{0.1} \mathrm{CuMg}(\mathrm{s}) \\
+\infty(\mathrm{Al}-8.8 \% \mathrm{Li}-0.5 \% \mathrm{Cu}-0.8 \% \mathrm{Mg}-0.1 \% \mathrm{Be})^{\mathrm{reg}}(\mathrm{s})\end{array}$ & -65.50 \\
\hline
\end{tabular}

\subsubsection{Calculation of Strain Energy and Nucleation Rate}

$\mathrm{S}^{\prime}$ has been reported to be partially coherent with $\mathrm{Al}(\alpha)$ matrix [44], however, the degree of coherency for $S^{\prime} / \mathrm{Al}(\alpha)$ interface is still unknown. In this case, incoherent case is assumed, and 
Nabarro [33] has shown that for incoherent precipitate the strain energy is given by Eq. (15). S particles are assumed to be rods with semi axes $r$ (radius) and c (length). Since $f(c / r)=3 / 4$ for rodlike precipitates in Eq. (15), the strain energy (W) for $\mathrm{S}$ nucleation is given by

$$
W=\frac{1}{2} \mu_{m}\left(\frac{\Delta V}{V}\right)^{2}
$$

The inclusion of $W$ in the free energy of formation of rod-shaped, incoherent $\mathrm{S}$ particle is performed by substituting expressions for the volume $\left(V=\pi r^{2} c\right)$ and surface area $\left(A=2 \pi r c+2 \pi r^{2}\right)$ into Eq. (14), which gives

$$
\Delta G=\pi r^{2} c\left(\Delta G_{V}+W\right)+\left(2 \pi r c+2 \pi r^{2}\right) \gamma
$$

Minimizing $\Delta \mathrm{G}$ with respect to $\mathrm{r}$ and $\mathrm{c}$ gives the values of $\mathrm{r}$ and $\mathrm{c}$ characteristic of the criticalsized nucleus of most favorable shape,

$$
\begin{aligned}
& r^{*}=-\frac{2 \gamma}{\Delta G_{V}+W} \\
& c^{*}=-\frac{4 \gamma}{\Delta G_{V}+W}
\end{aligned}
$$

and $\Delta G^{*}$ becomes (for $\Delta G_{V} \approx \Delta S_{V} \Delta T$ )

$$
\Delta G^{*}=\frac{8 \pi \gamma^{3}}{\left(-\Delta S_{V} \Delta T+W\right)^{2}}
$$

The relative nucleation rates of $\mathrm{Al}_{1.99} \mathrm{~V}_{0.01} \mathrm{CuMg}$ and $\mathrm{Al}_{1.9} \mathrm{Be}_{0.1} \mathrm{CuMg}$ to $\mathrm{Al}_{2} \mathrm{CuMg}$ are calculated by inserting $\Delta G^{*}$ values into Eq. (1). The $\mathrm{S}^{\prime} / \mathrm{Al}(\alpha)$ interfacial energy $(\gamma)$ is not available, and for the purpose of the calculation $\gamma=1.0 \times 10^{-5} \mathrm{~J} / \mathrm{cm}^{2}$ is used for the compounds, which is in the range of $1.0 \times 10^{-6}$ to $2.5 \times 10^{-5} \mathrm{~J} / \mathrm{cm}^{2}$ reported for similar interfaces when the lattice misfit is less than 1 $\%$ [151]. An estimation of $\gamma$ for $\mathrm{S}^{\prime} / \mathrm{Al}(\alpha)$ interface based on the $\mathrm{S}^{\prime}$ coarsening data (resistivity and TEM) in this work shows the same order of magnitude. The calculations of strain energy, $\Delta G^{*}$,

\begin{tabular}{|c|c|c|c|c|c|c|}
\hline Phase & $\begin{array}{c}V \\
\mathrm{~cm}^{3} / \text { g-atom }\end{array}$ & $\Delta V / V$ & $\begin{array}{c}W \\
\mathrm{~J} / \mathrm{cm}^{3}\end{array}$ & $\begin{array}{l}\left|\Delta S_{V}\right| \\
\mathrm{J} / \mathrm{cm}^{3}\end{array}$ & $\begin{array}{c}G^{*} \\
\mathrm{X} 10^{-19} \mathrm{~J}\end{array}$ & $\dot{N} / \dot{N}_{s}$ \\
\hline $\mathrm{Al}$ & 9.82 & -- & -- & -- & -- & - \\
\hline $\mathrm{S}$ in 8090 alloy & 9.95 & +0.013 & 2.41 & 1.54 & $\begin{array}{c}0.99 \\
(T=330 \mathrm{~K}) \\
\end{array}$ & -- \\
\hline $\mathrm{S}-\mathrm{V}$ in $60 \mathrm{~V}$ alloy & 9.98 & +0.016 & 3.65 & 1.56 & $\begin{array}{c}0.96 \\
(T=330 \mathrm{~K}) \\
\end{array}$ & $\begin{array}{l}N_{S-V} / \dot{N}_{S} \\
=1.60\end{array}$ \\
\hline $\begin{array}{c}\text { S-Be in } 15 B e \\
\text { alloy }\end{array}$ & 9.96 & +0.014 & 2.79 & 1.64 & $\begin{array}{c}0.87 \\
(T=330 \mathrm{~K}) \\
\end{array}$ & $\begin{array}{l}N_{S-B e} / \dot{N}_{S} \\
\quad=6.54\end{array}$ \\
\hline $\mathrm{S}$ in $60 \mathrm{~V}$ alloy ${ }^{*}$ & 9.95 & +0.013 & 2.41 & 1.54 & $\begin{array}{c}0.89 \\
(T=346 \mathrm{~K})\end{array}$ & $\begin{array}{l}\dot{N}_{S^{*}} / \dot{N}_{S} \\
=4.78\end{array}$ \\
\hline
\end{tabular}
and relative nucleation rate are detailed in Appendix II, and the results are summarized in Table 4.

Table 4. Strain energy, $\Delta G^{*}$ and relative nucleation rate of $\mathrm{S}$ phase in alloys at $190{ }^{\circ} \mathrm{C}$

$$
\left(\gamma_{S^{\prime} / A l(\alpha)}=1.0 \times 10^{-5} \mathrm{~J} / \mathrm{cm}^{2}\right)
$$




\begin{tabular}{|l|l|l|l|l|c|c|}
\hline S-V in 60V alloy & 9.98 & +0.016 & 3.65 & 1.56 & $\begin{array}{c}0.87 \\
(T=346 \mathrm{~K})\end{array}$ & $\begin{array}{c}N_{S-V^{*}} / \dot{N}_{S} \\
=6.54\end{array}$ \\
\hline
\end{tabular}

* S phase nucleation in the alloy with the decreased solubilities of $\mathrm{Cu}$ and $\mathrm{Mg}$ resulting from the $0.6 \% \mathrm{~V}$ addition.

To consider the effect of decreased solubilities of $\mathrm{Cu}$ and $\mathrm{Mg}$ in $\mathrm{Al}(\alpha)$ on the nucleation rate of S' phase in 8090 alloy, two additional cases are calculated for the nucleation rate:

(1) nucleation of $\mathrm{Al}_{2} \mathrm{CuMg}$ in the $60 \mathrm{~V}$, using the $\mathrm{V}$-reduced solubilities of $\mathrm{Cu}$ and $\mathrm{Mg}$ in $\operatorname{Al}(\alpha)$.

(2) nucleation of $\mathrm{Al}_{1.99} \mathrm{~V}_{0.01} \mathrm{CuMg}$ in the $60 \mathrm{~V}$ alloy, using the $\mathrm{V}$-reduced solubilities of $\mathrm{Cu}$ and $\mathrm{Mg}$ in $\mathrm{Al}(\alpha)$.

It is evident from Eq. (19) that the mixing component of the nucleation entropy is determined by the compositions of both precipitate ( $\mathrm{S}^{\prime}$ phase) and matrix $(\mathrm{Al})$, and that a restriction in solubility of principal alloying components in the $\mathrm{Al}(\alpha)$ can significantly increase the nucleation entropy. A restriction in the solubilities of $\mathrm{Cu}$ and $\mathrm{Mg}$ in $\mathrm{Al}(\alpha)$ would result in a higher value of $\left|\Delta S_{M}\right|$ for $\mathrm{S}$ ' nucleation when solution temperature is below the solvus line of the alloy. However, the solution temperature used in this work $\left(590{ }^{\circ} \mathrm{C}\right)$ is higher than the actual solvus temperature of the alloy, since no $\mathrm{S}$ phase was found in the solution treated and quenched alloy, and the nucleation entropy will not be changed by the decreased solubilities. However, for the 60V alloy, $\mathrm{V}$ saturation of $\mathrm{Al}(\alpha)$ occurs, as indicated by the presence of $\mathrm{Al}_{3} \mathrm{~V}$ phase in the microstructure [39], which will result in the decreased solubilities of $\mathrm{Cu}$ and $\mathrm{Mg}$ in $\mathrm{Al}(\alpha)$ to shift the solvus line of the $\mathrm{S}$ phase in $\mathrm{Al}(\alpha)$. The restriction in the $\mathrm{Cu}$ and $\mathrm{Mg}$ solubilities for the $60 \mathrm{~V}$ alloy containing $\mathrm{Li}$ is no known. However, for the purpose of illustrating the effect on nucleation rate resulting from the restriction in solubility, it will be assumed that a $5 \%$ increase in $\Delta T$ is resulted for the $60 \mathrm{~V}$ alloy. The calculated results are shown in Table 4.

The results in Table 4 show that, although the $\mathrm{V}$ and $\mathrm{Be}$ incorporations in the precipitate compound increase the strain energy of $\mathrm{S}$ nucleation, the increases in nucleation entropy by $\mathrm{V}$ and Be more than offset the strain energy effect to give net decreases in the free energy of formation of the critical-sized nucleus, and the corresponding increases in the nucleation rates. A $5 \%$ increase supercooling alone is shown to increase the nucleation rate of $\mathrm{Al}_{2} \mathrm{CuMg}$ more than four times. When the incorporation of 0.2 at $\% \mathrm{~V}$ into $\mathrm{S}$ phase is coupled with the decreased solubilities of $\mathrm{Cu}$ and $\mathrm{Mg}$ in $\mathrm{Al}(\alpha)$, a more significant increase of nucleation rate is obtained (6.54 times).

\subsubsection{Microstructure and Mechanical Properties}

Fig. 1 is a series of TEM micrographs showing the effects of $\mathrm{V}$ and Be additions on the distribution and density of $S^{\prime}$ phase in peak-aged conditions. To estimate the average length and density of the S' laths, a minimum of three areas was sampled and between 200 to 500 particles were counted for each alloy. The results are summarized in Table 5. Fig. 1(a) shows clear evidence of heterogeneous nucleation of S' phase on dislocations (see marked areas) in 8090 alloy. The $S^{\prime}$ phase has been known to nucleate preferentially on dislocations, since strains associated with the dislocations reduce the overall strain energy associated with this partially 
coherent precipitate. The TEM micrographs also show a higher density and refinement of $\mathrm{S}^{\prime}$ phase in V- and Be-containing alloys (Figs. 1(c) and (d), Table 5) and suggest an enhanced nucleation rate for $\mathrm{S}^{\prime}$ precipitation in microalloyed specimens $(60 \mathrm{~V}$ and $15 \mathrm{Be})$.

The mechanical properties for the alloys in their peak-aged conditions are also given in Table 5. For base alloy 8090, the tensile data agree well with the results reported by White et al [44]. The elongation to failure of the alloy was found low, and no necking phenomenon was observed before fracture. For the alloy containing 0.60V, significantly higher YS (459 MPa), UTS (512 $\mathrm{MPa}$ ), and $\mathrm{E}_{\mathrm{f}}(4.6 \%)$ are obtained over the base alloy, and a slight but notable necking is observed before fracture. For the Be-containing alloy, even higher YS (480 MPa) and UTS (528 $\mathrm{MPa})$ are achieved over the base alloy without a reduction in ductility $(2.5 \%)$.

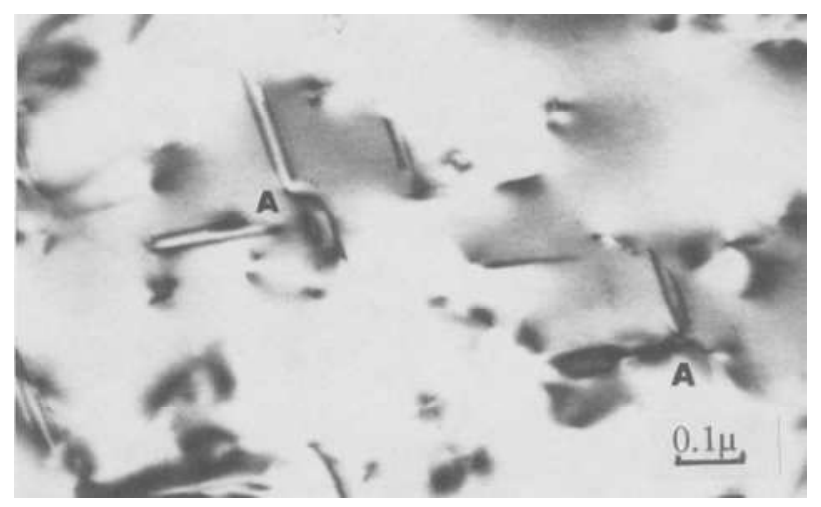

(a) 8090 alloy

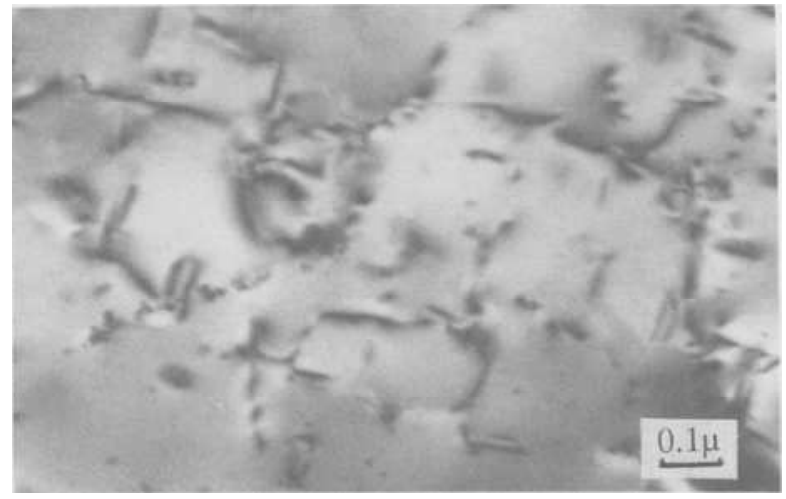

(b) $8090+0.6 \mathrm{~V}$

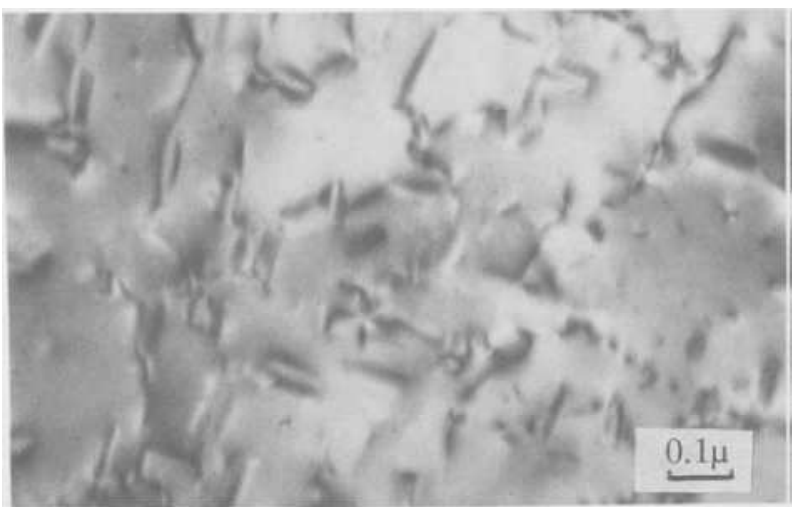

(c) $8090+15 \mathrm{Be}$ 
Fig. 1. TEM micrographs showing S' phase in peak-aged conditions at $190{ }^{\circ} \mathrm{C}$, bright-field, foils close to [001]. (a) 8090, showing heterogeneous nucleation of $\mathrm{S}^{\prime}$ phase on dislocations (marked $\mathrm{A}$ ); (b) and (c) $60 \mathrm{~V}$ and $15 \mathrm{Be}$, respectively, showing refinement of $\mathrm{S}^{\prime}$ by $\mathrm{V}$ and Be additions [38].

Table 5. The average length and particle density of S' laths in peak-aged conditions

\begin{tabular}{|c|c|c|c|c|c|}
\hline Alloy & $\begin{array}{c}\text { S' length, } \\
\mathrm{nm}\end{array}$ & $\begin{array}{c}\text { S' density, } \\
\text { X } 10^{12} \mathrm{~m}^{-2}\end{array}$ & $\begin{array}{c}\text { Yield Strength, } \\
\mathrm{MPa}\end{array}$ & $\begin{array}{c}\text { UTS, } \\
\mathrm{MPa}\end{array}$ & $\begin{array}{c}\text { Elongation, } \\
\%\end{array}$ \\
\hline 8090 & $161 \pm 26$ & $1.25 \pm 0.08$ & $372 \pm 22$ & $468 \pm 27$ & $2.5 \pm 0.2$ \\
\hline $8090+0.6 \mathrm{~V}$ & $102 \pm 34$ & $1.88 \pm 0.05$ & $421 \pm 14$ & $509 \pm 21$ & $5.0 \pm 0.5$ \\
\hline $8090+0.15 \mathrm{Be}$ & $96 \pm 26$ & $3.13 \pm 0.17$ & $480 \pm 37$ & $528 \pm 35$ & $4.5 \pm 0.5$ \\
\hline
\end{tabular}

\section{Computational Thermodynamics Approach}

\subsection{The CALPHAD Approach}

It is clear from the above section that certain assumptions (e.g., regular solution for dilute alloys) had to be made in the classical thermodynamics approach, which are not necessary in modern computational thermodynamics. Originated from the early work of Kaufman and Bernstein [45], the CALPHAD approach [46, 47], based on computational thermodynamics, has matured over the past few decades to calculate phase diagrams and predict phase equilibrium for complex multi-component systems. Many commercial software packages, such as ThermoCalc [48], FactSage [49] and Pandat [50], have become important tools used in the development of new materials and products.

The CALPHAD approach is based on the thermodynamic description of an alloy system, which denotes a set of thermodynamic parameters for all phases in the system. In a ternary alloy system, the phases of interest are solid, liquid and intermetallic phases. The Gibbs energy per mole of a liquid or a substitutional solid solution is [47],

$$
G_{m}^{\phi}=\sum_{i} x_{i}^{\circ} G_{i}^{\phi}+R T \sum_{i} x_{i} \ln x_{i}+\Delta^{x s} G_{m}^{\phi}
$$

The first term on the right-hand side (RHS) of Eq. (25) is the Gibbs energy of the component elements in the reference state at a constant temperature $(T)$ and a pressure $(P)$ of 1 bar, the second the ideal Gibbs energy of mixing, and the third the excess Gibbs energy. The last term is described by the Redlich-Kister equation as given below. The number of the parameters is limited to three at constant $T$ and $P$ of 1 bar.

$$
\Delta^{x s} G_{m}^{\phi}\left(x_{i}, T\right)=x_{i} x_{j} \sum_{v=0}^{v=2}{ }^{(v)} \lambda\left(x_{i}-x_{j}\right)^{v}
$$


The symbols $G_{m}, R, \lambda, x_{i}, x_{j}$ are, respectively, the molar Gibbs energy, universal gas constant, model parameters, mole fraction of component $i$ and that of component $j$. For the intermetallic phases with more than one sublattice, the compound energy formalism is used and given below.

$$
G_{m}=\sum y_{p}^{(i)} y_{q}^{(j)} G_{(p: q)}+R T \sum f_{i} y_{p}^{(i)} \ln y_{p}^{(i)}+\sum y_{p}^{(i)} y_{q}^{(i)} y_{r}^{(j)} \sum_{k} L_{(p, q, r)}^{(k)}\left(y_{p}^{(i)}-y_{q}^{(i)}\right)^{k}
$$

where $G_{m}$ is the Gibbs energy expressed as a function of the concentrations of the sublattice species. The first term on the RHS of Eq. (27) is the reference term, the second ideal Gibbs energy of mixing on the sublattices, and the last term the excess Gibbs energy on the sublattice. The $y$ 's are the mole fractions of the species on a specific sublattice, $f_{i}$ the fraction of a specific sublattice within the crystal, and $L_{(p, q: r)}$ 's are the model parameters. The superscripts $(i),(j)$ specify the sublattice and the subscripts $p$ and $q$ the species on the sublattices.

The above description of alloy systems was used in the Pandat code [50] for phase equilibria calculations in this paper. This section demonstrates examples of applying computational thermodynamics and CALPHAD modeling in the development of new creep-resistant magnesium alloys using the Pandat code and its PanMagnesium database [50].

\section{2. $\underline{\text { Mg-Al System }}$}

Aluminum is the most widely used alloying addition in magnesium for strengthening and castability. Fig. 2 shows a calculated $\mathrm{Mg}$-Al phase diagram. There are two eutectic reactions that are important to the phase constitution of $\mathrm{Mg}-\mathrm{Al}$ binary alloys:

1) At $450^{\circ} \mathrm{C} \quad \mathrm{L} \rightarrow \mathrm{Al}+\mathrm{Mg}_{2} \mathrm{Al}_{3}$

2) At $436^{\circ} \mathrm{C} \quad \mathrm{L} \rightarrow \mathrm{Mg}+\mathrm{Mg}_{17} \mathrm{Al}_{12}$

Commercial cast and wrought magnesium alloys (AZ91, AM60 and AZ31) contain less than $10 \% \mathrm{Al}$, and the microstructure of these $\mathrm{Mg}-\mathrm{Al}$ based alloys is generally characterized by the formation of $\mathrm{Mg}_{17} \mathrm{Al}_{12}$ phase. The low eutectic temperature $\left(436^{\circ} \mathrm{C}\right)$ of $\mathrm{Mg}_{17} \mathrm{Al}_{12}$ phase limits the application of $\mathrm{Mg}$-Al alloys to temperatures below $125^{\circ} \mathrm{C}$, above which the discontinuous precipitation the $\mathrm{Mg}_{17} \mathrm{Al}_{12}$ phase leads to substantial creep deformation [2]. Therefore, possible approaches for improving creep resistance in $\mathrm{Mg}$-Al based alloys include: 1) suppressing the formation of the $\mathrm{Mg}_{17} \mathrm{Al}_{12}$ phase; 2) pinning grain boundary sliding; and 3) slowing solute diffusion in the magnesium matrix.

\section{3. $\mathrm{Mg}-\mathrm{Al}-\mathrm{Ce}$ System}

Earlier experimental work [51,52] has shown that additions of RE in the form of mischmetal can improve the creep resistance of $\mathrm{Mg}-\mathrm{Al}$ based alloys, especially when the aluminium content was low (less than 4\%). This led to the development of AE series alloys, AE42 (Mg-4Al-2RE) and AE44 (Mg-4Al-4RE) where the mischmetal RE generally contains more than $60 \%$ Ce (balance $\mathrm{La}, \mathrm{Nd}$ and Pr). Fig. 3 shows the calculated liquidus projection of the $\mathrm{Mg}$-Al-Ce system in the 
Mg-rich corner. Generally, the liquidus temperature decreases with Al addition (up to at least about $10 \%$ ) and $\mathrm{Ce}$ (up to at least about 10\%), with the following two type II invariant reactions marked at $598^{\circ} \mathrm{C}$ and $562^{\circ} \mathrm{C}$, respectively:

1) At $598^{\circ} \mathrm{C} \quad \mathrm{L}+(\mathrm{Al}, \mathrm{Mg})_{2} \mathrm{Ce} \rightarrow \mathrm{Mg}+\mathrm{Mg}_{12} \mathrm{Ce}$

2) At $562^{\circ} \mathrm{C} \quad \mathrm{L}+(\mathrm{Al}, \mathrm{Mg})_{2} \mathrm{Ce} \rightarrow \mathrm{Mg}+\mathrm{Al}_{11} \mathrm{Ce}_{3}$
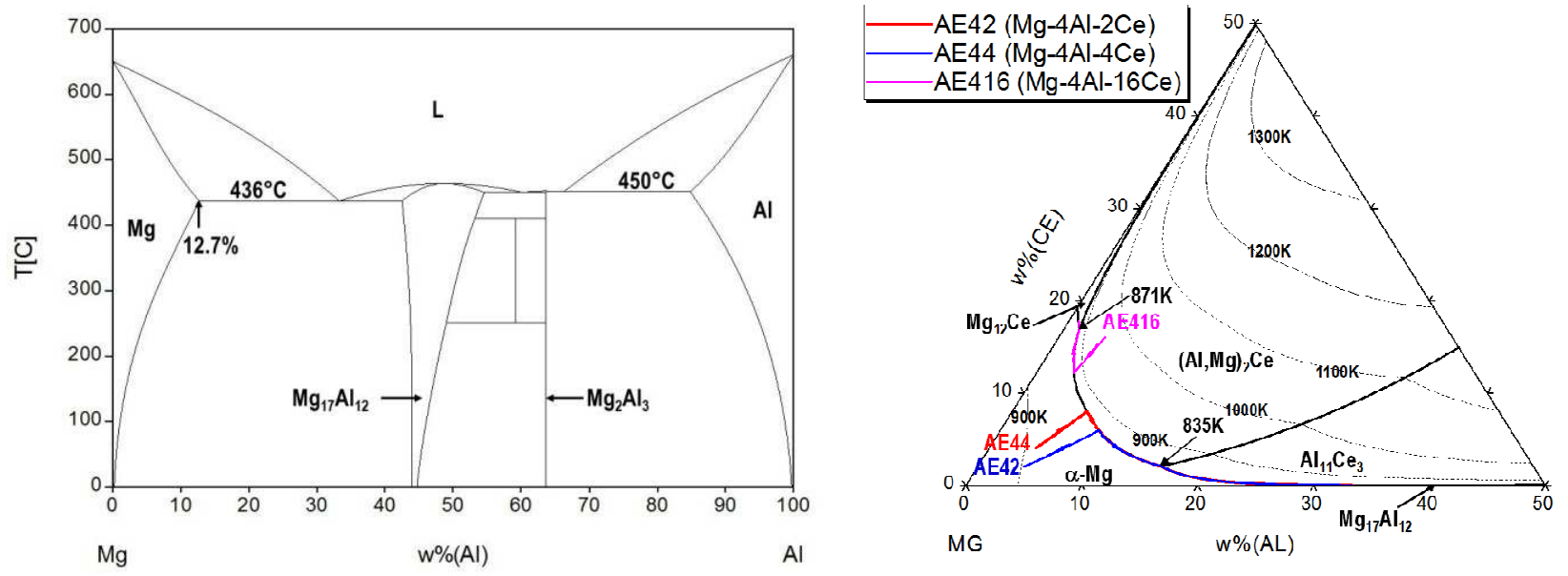

Fig. 2. Calculated Mg-Al phase diagram.

Fig. 3. Calculated Mg-Al-Ce liquidus projection and solidification paths of experimental Mg-Al-Ce alloys.

The calculated solidification paths of AE42 and AE44 alloys using the Scheil model, based on the assumption of complete mixing in the liquid but no diffusion in the solid, are superimposed in the phase diagram shown in Fig. 3. Based on the simulation results, the solidification sequence for both alloys is as follows:

1) Nucleation of primary magnesium: $\quad \mathrm{L} \rightarrow \mathrm{Mg}$

2) Monovariant eutectic reaction:

$\mathrm{L} \rightarrow \mathrm{Mg}+(\mathrm{Al}, \mathrm{Mg})_{2} \mathrm{Ce}$

3) Type II invariant reaction:

$\mathrm{L}+(\mathrm{Al}, \mathrm{Mg})_{2} \mathrm{Ce} \rightarrow \mathrm{Mg}+\mathrm{Al}_{11} \mathrm{Ce}_{3}$

4) Ternary eutectic reaction:

$\mathrm{L} \rightarrow \mathrm{Mg}+\mathrm{Al}_{11} \mathrm{Ce}_{3}+\mathrm{Mg}_{17} \mathrm{Al}_{12}$

It should be pointed out that Type II invariant reaction will be bypassed under the Scheil conditions because it requires solid-state diffusion through the growing reaction product layer, $\mathrm{Mg}+\mathrm{Al}_{11} \mathrm{Ce}_{3}$, in this case. It is clear that the additions of 2-4\% $\mathrm{Ce}$ to $\mathrm{Mg}-\mathrm{Al}$ alloys have resulted in the formation of $\mathrm{Al}_{11} \mathrm{Ce}_{3}$ in addition to the $\mathrm{Mg}_{17} \mathrm{Al}_{12}$ phase in the $\mathrm{Mg}$ - $\mathrm{Al}$ binary system. Fig. 4(a) shows the effect of $\mathrm{Ce}$ addition to $\mathrm{Mg}-4 \mathrm{Al}$ alloy on the fraction of $\mathrm{Mg}_{17} \mathrm{Al}_{12}$ phase in the ternary alloy as calculated using the Scheil model. This indicates that it takes about $15 \%$ Ce to completely suppress the formation of $\mathrm{Mg}_{17} \mathrm{Al}_{12}$ phase in the $\mathrm{Mg}-4 \mathrm{Al}$ alloy. Similar calculations were made for Mg-Al-Ce alloys with various Al and Ce contents, Fig. 4(b), which can be used as guidance to design the ternary alloy avoiding $\mathrm{Mg}_{17} \mathrm{Al}_{12}$ phase formation for elevated temperature applications. Fig. 3 also shows the solidification sequence of AE416 (Mg-4Al-16Ce) alloy as follows: 

1) Nucleation of $(\mathrm{Al}, \mathrm{Mg})_{12} \mathrm{Ce}$ phase:
$\mathrm{L} \rightarrow(\mathrm{Al}, \mathrm{Mg})_{2} \mathrm{Ce}$
2) Monovariant eutectic reaction:
$\mathrm{L} \rightarrow \mathrm{Mg}+(\mathrm{Al}, \mathrm{Mg})_{2} \mathrm{Ce}$
3) Type II invariant reaction:
$\mathrm{L}+(\mathrm{Al}, \mathrm{Mg})_{2} \mathrm{Ce} \rightarrow \mathrm{Mg}+\mathrm{Mg}_{12} \mathrm{Ce}$
4) Binary eutectic reaction:
$\mathrm{L} \rightarrow \mathrm{Mg}+\mathrm{Mg}_{12} \mathrm{Ce}$

The eutectic temperatures for $\mathrm{Al}_{11} \mathrm{Ce}_{3},(\mathrm{Al}, \mathrm{Mg})_{2} \mathrm{Ce}$ and $\mathrm{Mg}_{12} \mathrm{Ce}$ phases are calculated as $560^{\circ} \mathrm{C}$, $622^{\circ} \mathrm{C}$ and $867^{\circ} \mathrm{C}$, respectively, which are all significantly higher than of the $\mathrm{Mg}_{17} \mathrm{Al}_{12}$ phase $\left(436^{\circ} \mathrm{C}\right)$. The Scheil model was also used to calculate the fraction of phases formed in the three AE alloys according to the above solidification paths. Fig. 5 shows as-cast microstructure of AE44 alloy, showing primary $\mathrm{Mg}$ grains surrounded by eutectic $\mathrm{Al}_{11} \mathrm{Ce}_{3}$ phase (mostly) and a small amount of $\mathrm{Mg}_{17} \mathrm{Al}_{12}$ phase. The results of these calculations are summarized in Table 6 and compared with commercial AM50 (Mg-5Al-0.3Mn) alloy. In AE alloys, 4-5\% Al is generally needed for die castability, while it is very expensive to use $16 \%$ Ce (e.g., AE416 alloy) to suppress formation of $\mathrm{Mg}_{17} \mathrm{Al}_{12}$ [53]. On the other hand, $\mathrm{AE} 44$ alloy has significantly lower fraction of $\mathrm{Mg}_{17} \mathrm{Al}_{12}$, and, thus, much better high-temperature strength compared with AE42 or AM50 alloy. Therefore, AE44 alloy was selected for the Corvette engine cradle application where the operating temperature would approach $150^{\circ} \mathrm{C}$ [54].

Table 6. Scheil simulation (vol.\%) of Mg-Al-Ce alloys (Baseline: AM50 alloy)

\begin{tabular}{|r|c|c|c|c|}
\hline Alloy & $(\mathrm{Al}, \mathrm{Mg})_{2} \mathrm{Ce}$ & $\mathrm{Al}_{11} \mathrm{Ce}_{3}$ & $\mathrm{Mg}_{17} \mathrm{Al}_{12}$ & $\mathrm{Mg}_{12} \mathrm{Ce}$ \\
\hline AM50 & - & - & 4.3 & \\
\hline AE42 & 0.9 & 0.2 & 1.8 & \\
\hline AE44 & 2.0 & 0.1 & 1.0 & \\
\hline AE416 & 9.5 & 0 & 0 & 0.7 \\
\hline
\end{tabular}

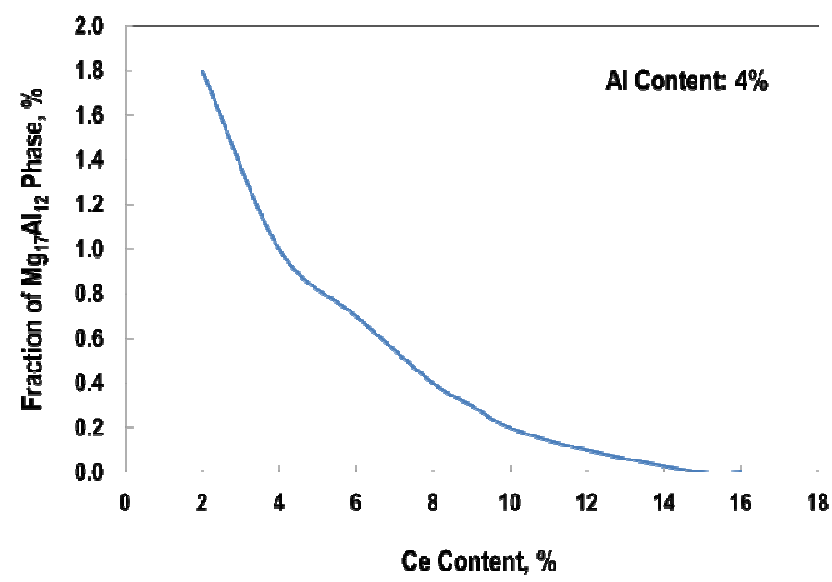

Fig. 4(a). Effect of Ce content on the fraction of $\mathrm{Mg}_{17} \mathrm{Al}_{12}$ phase in $\mathrm{Mg}-4 \mathrm{Al}-\mathrm{Ce}$ alloys following solidification based on the Scheil simulation.

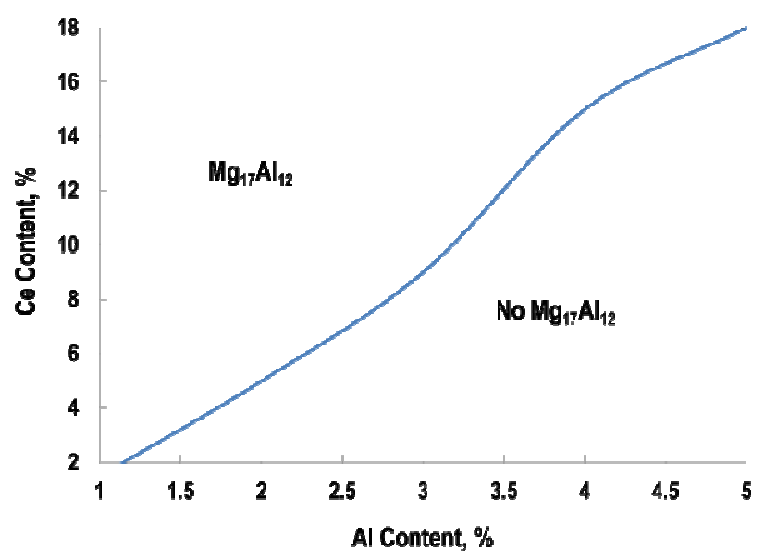

Fig. 4(b). Effect of $\mathrm{Ce}$ and $\mathrm{Al}$ content on the formation of $\mathrm{Mg}_{17} \mathrm{Al}_{12}$ phase in $\mathrm{Mg}-\mathrm{Al}-\mathrm{Ce}$ alloys following solidification based on the Scheil simulation. 


\subsection{Mg-Al-Ca System}

$\mathrm{Mg}$-Al-Ca system was investigated to replace the more expensive AE alloys. Fig. 6 shows a calculated liquidus projection of the $\mathrm{Mg}$-Al-Ca system, superimposed by the solidification paths of three Mg-Al-Ca alloys; AX51 (Mg-5Al-1Ca), AX52 (Mg-5Al-2Ca) and AX53 (Mg-5Al-3Ca), calculated using the Scheil model. Based on the simulation results, the solidification sequence for AX51 and AX52 alloys are as follows:

1) Nucleation of primary magnesium:

$\mathrm{L} \rightarrow \mathrm{Mg}$

2) Binary eutectic reaction:

$\mathrm{L} \rightarrow \mathrm{Mg}+(\mathrm{Mg}, \mathrm{Al})_{2} \mathrm{Ca}$

3) Type II invariant reaction:

$\mathrm{L}+(\mathrm{Mg}, \mathrm{Al})_{2} \mathrm{Ca} \rightarrow \mathrm{Mg}+\mathrm{Mg}_{17} \mathrm{Al}_{12}$

4) Binary eutectic reaction:

$\mathrm{L} \rightarrow \mathrm{Mg}+\mathrm{Mg}_{17} \mathrm{Al}_{12}$

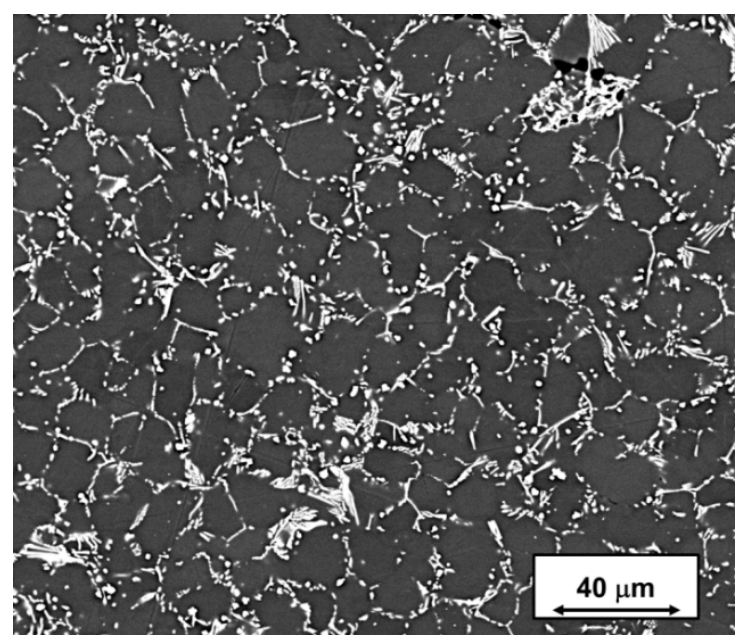

Fig. 5. SEM micrograph showing as-cast microstructure of AE44 alloy.

AX53 alloy has a different ternary eutectic reaction where $\mathrm{Mg}_{2} \mathrm{Ca}$ is formed instead of $\mathrm{Mg}_{17} \mathrm{Al}_{12}$, resulting in a slightly different solidification path:

1) Nucleation of primary magnesium:

$\mathrm{L} \rightarrow \mathrm{Mg}$

2) Binary eutectic reaction:

$\mathrm{L} \rightarrow \mathrm{Mg}+(\mathrm{Mg}, \mathrm{Al})_{2} \mathrm{Ca}$

3) Ternary eutectic reaction :

$\mathrm{L} \rightarrow \mathrm{Mg}+(\mathrm{Mg}, \mathrm{Al})_{2} \mathrm{Ca}+\mathrm{Mg}_{2} \mathrm{Ca}$ 


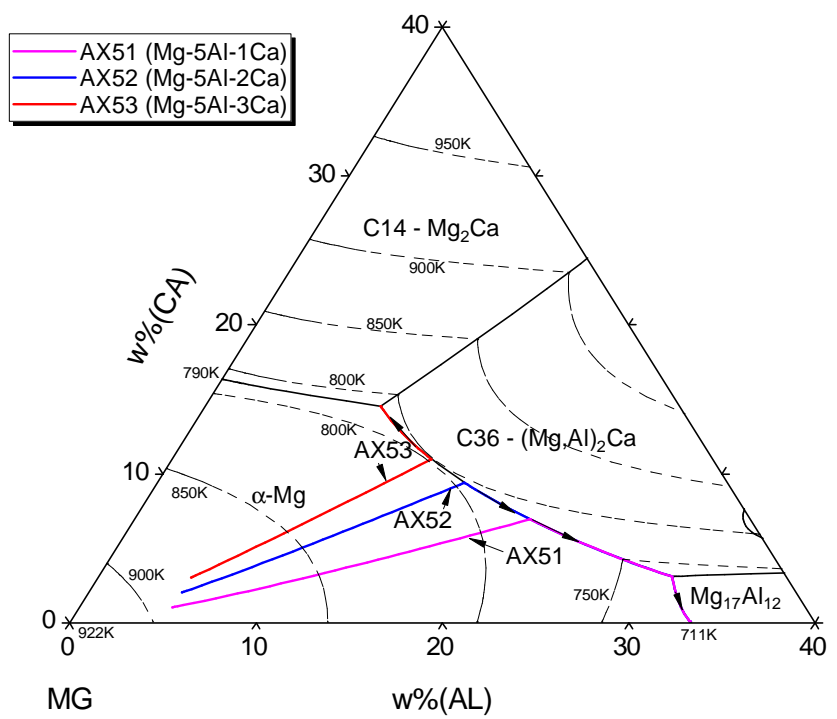

Fig. 6. Calculated Mg-Al-Ca liquidus projection and the solidification paths of the experimental Mg-Al-Ca alloys.

Fig. 6(a) and Table 7 show the effect of $\mathrm{Ca}$ on the fraction of $\mathrm{Mg}_{17} \mathrm{Al}_{12}$ phase formed in these alloys during solidification as determined by the Scheil simulation. It is evident that the $\mathrm{Ca}$ content has to be greater than $2.8 \%$ in order to completely suppress the formation of $\mathrm{Mg}_{17} \mathrm{Al}_{12}$ in the $\mathrm{Mg}-5 \mathrm{Al}$ alloy. Furthermore, the critical $\mathrm{Ca}$ contents were calculated for Mg-Al-Ca ternary alloys containing 3-9\% Al, and plotted in Fig. 6(b), which is an important composition map for optimizing creep-resistant alloys in this system.
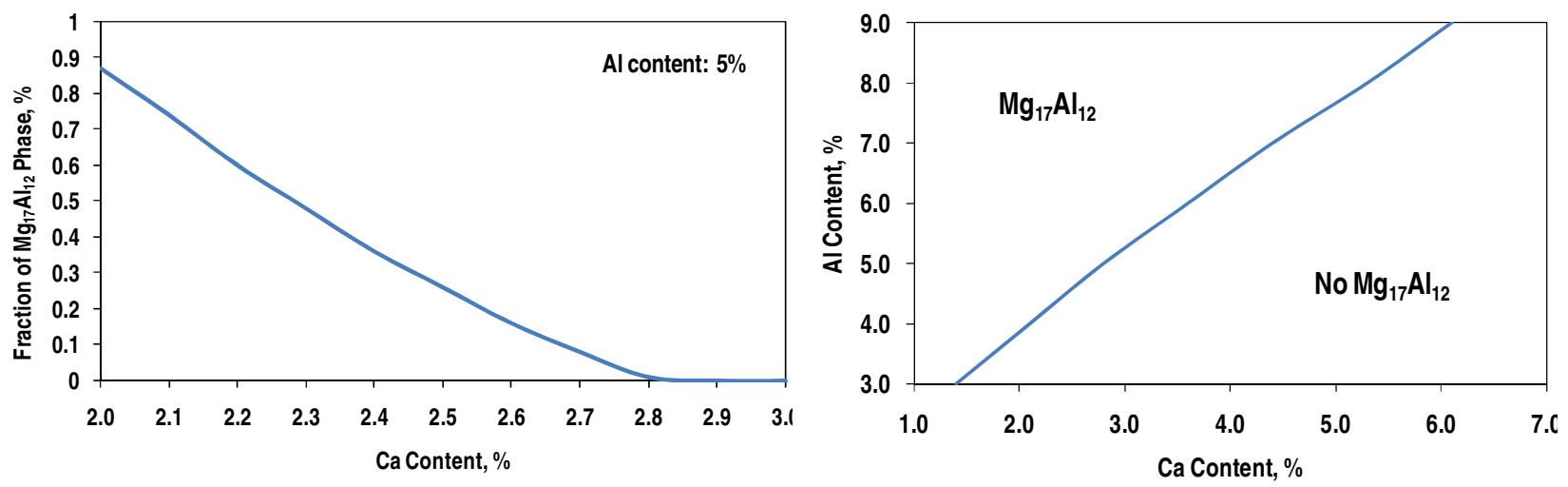

Fig. 6(a). Effect of Ca content on the fraction of $\mathrm{Mg}_{17} \mathrm{Al}_{12}$ phase in $\mathrm{Mg}-4 \mathrm{Al}-\mathrm{Ca}$ alloys following solidification based on the Scheil simulation.

Fig. 6(b). Effect of $\mathrm{Ca}$ and $\mathrm{Al}$ content on the formation of $\mathrm{Mg}_{17} \mathrm{Al}_{12}$ phase in $\mathrm{Mg}-\mathrm{Al}-\mathrm{Ca}$ alloys following solidification based on the Scheil simulation.

Table 7. Scheil simulation and experimental measurement results of second phases in $\mathrm{Mg}-\mathrm{Al}-\mathrm{Ca}$ and baseline AM50 alloys

\begin{tabular}{|c|c|c|c|c|c|}
\hline \multirow{2}{*}{ Alloy } & \multicolumn{4}{|c|}{ Scheil Calculation, vol\% } & Measurement, vol\% \\
\cline { 2 - 6 } & $(\mathrm{Mg}, \mathrm{Al})_{2} \mathrm{Ca}$ & $\mathrm{Mg}_{2} \mathrm{Ca}$ & $\mathrm{Mg}_{17} \mathrm{Al}_{12}$ & Total Fraction & Total Fraction \\
\hline AX51 & 2.0 & 0 & 2.7 & 4.7 & 5.5 \\
\hline AX52 & 4.1 & 0 & 0.9 & 5.0 & 5.8 \\
\hline
\end{tabular}




\begin{tabular}{|c|c|c|c|c|c|}
\hline AX53 & 5.8 & 0.1 & 0 & 5.9 & 6.2 \\
\hline AM50 & & & 4.3 & 4.3 & 4.8 \\
\hline
\end{tabular}

The presence of $(\mathrm{Mg}, \mathrm{Al})_{2} \mathrm{Ca}$ phase in the die-casting microstructure of $\mathrm{Mg}$-Al-Ca alloys [55] and $\mathrm{Mg}_{2} \mathrm{Ca}$ eutectic phase in AX53 (die casting) have been confirmed in previous experimental results $[55,56]$. While $\mathrm{C} 14$ is a complete hcp (hexagonal close packed) structure with $100 \%$ hexagonality, C36 is an intermediate structure between hcp and fcc (face centered cubic) with $50 \%$ hexagonality [56]. The role of $\mathrm{C} 14$ and $\mathrm{C} 36$ phases in creep resistance of $\mathrm{Mg}$-Al-Ca-based alloys has been discussed in previous investigations $[55,56]$. The calculated $\mathrm{Mg}-\mathrm{Ca}$ binary diagram suggests that the $\mathrm{C} 14$ phase has a high eutectic temperature $\left(517^{\circ} \mathrm{C}\right)$ and melting point $\left(710^{\circ} \mathrm{C}\right)$ and can thus exhibit better thermal stability. The C36 phase is more stable than C14 and $\mathrm{Mg}_{17} \mathrm{Al}_{12}$ phases in terms of the relative change in the eutectic structure during annealing. This implies an advantage of the $\mathrm{C} 36$ phase as a strengthener at grain boundaries in creep-resistant alloys. This computational alloy design approach confirms the 2-3\% Ca present in these alloys to have significant fractions of $\mathrm{C} 14$ and $\mathrm{C} 36$ phases for creep resistance, and the AX53 alloy to have improved castability due to its reduced freeze range compared with AX51 and AX52 alloys [57].

Fig. 7 compares the tensile yield strength at room temperature and $175^{\circ} \mathrm{C}$ and the creep strength at $175^{\circ} \mathrm{C}$ (stress to produce $0.1 \%$ creep strain in 100 hours) of all four alloys. Compared with the commercial AM50 alloy, the tensile strength and creep strength of Mg-Al-Ca alloys are significantly improved, which is due to the strengthening effect of $(\mathrm{Mg}, \mathrm{Al})_{2} \mathrm{Ca}$ phase [55]. The increase in tensile yield strength of the AX alloys at room and elevated temperature $\left(175^{\circ} \mathrm{C}\right)$ with increasing $\mathrm{Ca}$ content, is attributed to an increase in volume fraction of the $(\mathrm{Mg}, \mathrm{Al})_{2} \mathrm{Ca}$ phase. Fig. 7 also shows that the creep strengths of the AX52 and AX53 alloys are similar, and are significantly higher than that of the AX51 alloy. This is due to the fact that the AX51 alloys contains a significant fraction of the undesirable $\mathrm{Mg}_{17} \mathrm{Al}_{12}$ phase, which is minimal in the AX52 alloy, and not present in the AX53 alloy (Table 7). AX53 alloy is presently being developed by GM for automotive powertrain applications. 

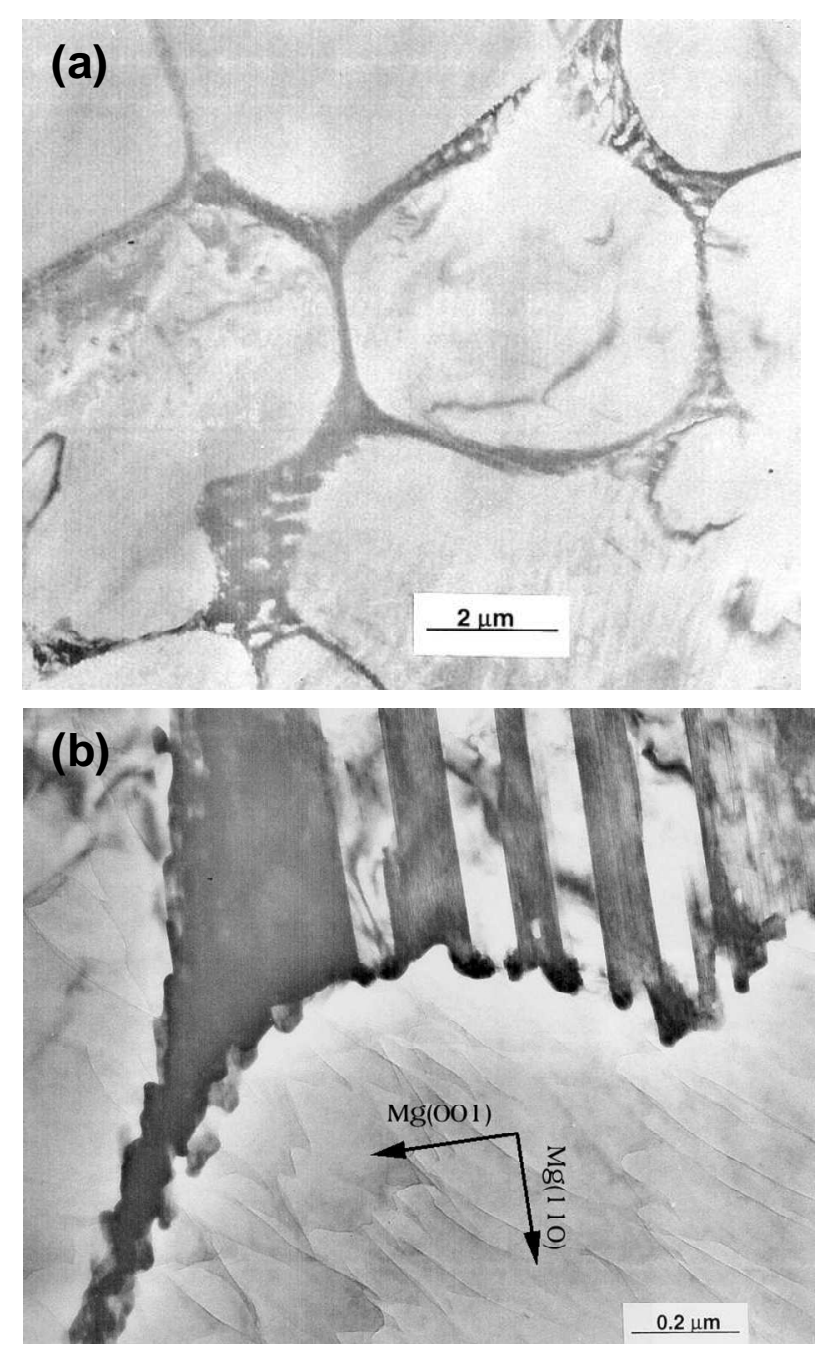

Fig. 8. TEM micrographs showing (a) the distribution, and (b) the morphology of the grain boundary phase, $(\mathrm{Mg}, \mathrm{Al})_{2} \mathrm{Ca}$, in the die cast microstructure of the AX53 alloy [55]. 


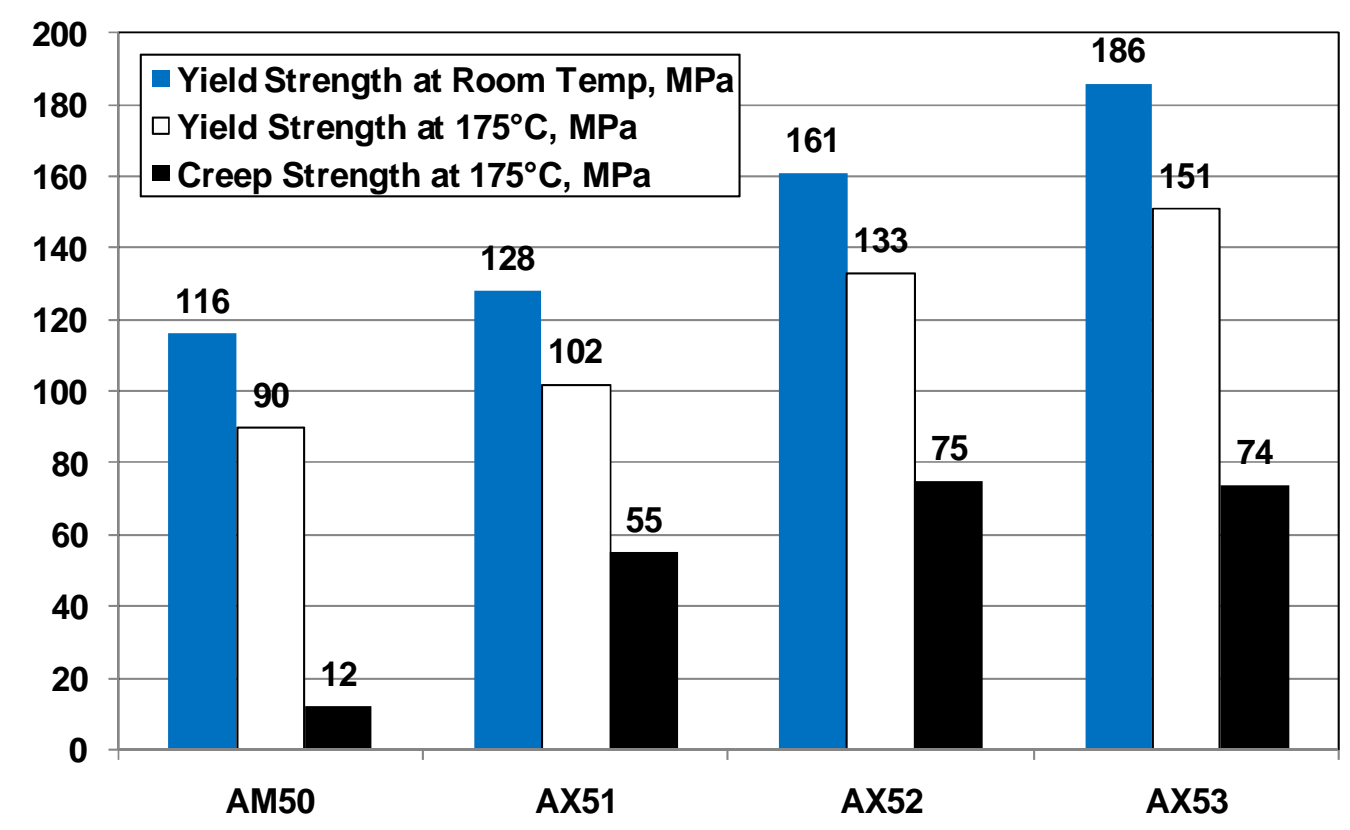

Fig. 7. Tensile yield strength at room temperature and $175^{\circ} \mathrm{C}$ and creep strength at $175^{\circ} \mathrm{C}$ (stress to produce $0.1 \%$ creep strain in 100 hours) of $\mathrm{AX}$ and AM50 alloys [57].

\section{The ICME (Integrated Computational Materials Engineering) Approach}

In the last few years, CALPHAD modeling has been linked to first-principles calculations of energetics (based on density functional theory) [61] and diffusion databases [62] for microstructure simulation and performance prediction. This section provides examples of firstprinciples calculations, mobility database development, microstructure simulation for accelerated development of magnesium alloys.

\subsection{First-Principles Calculations}

Significant efforts on integrating first-principles calculations and the CALPHAD modeling have been summarized in a recent review by Liu [61]. One concurrent effort, Open Quantum Materials Database (OQMD) led by Wolverton (http://oqmd.org/), offers its large public compilation of DFT data computed using standardized conditions for many materials systems. In the case of magnesium alloys as discussed in Section 3.4, the addition of Ca has been found to improve the creep resistance of $\mathrm{Mg}-\mathrm{Al}$ based alloys [55], owing to the replacement of the $\mathrm{Mg}_{17} \mathrm{Al}_{12}$ phase by more stable laves phases $[56,57]$. Experimental work and first-principles calculations [58-60] confirmed the existence of a $\mathrm{C} 36$ laves phase in the $\mathrm{Al}_{2} \mathrm{Ca}-\mathrm{Mg}_{2} \mathrm{Ca}$ pseudobinary system, in addition to the $\mathrm{C} 14-\mathrm{Mg}_{2} \mathrm{Ca}$ and $\mathrm{C} 15-\mathrm{Al}_{2} \mathrm{Ca}$ laves phases. However, there was no thermodynamic data available for phase equilibrium calculations. A special quasi-random structures (SQS) for all three laves phases were constructed. The structures possess local pair and multisite correlation functions that mimic those of the corresponding random structures. Firstprinciples calculations were carried out based on the SQS developed to predict the enthalpy of formation in the $\mathrm{Al}_{2} \mathrm{Ca}-\mathrm{Mg}_{2} \mathrm{Ca}$ pseudo-binary system. Two sublattice model $(\mathrm{Mg}, \mathrm{Al})_{2} \mathrm{Ca}$ is 
chosen for these three laves phases, $\mathrm{C} 14, \mathrm{C} 15$, and $\mathrm{C} 36$. The random mixing of $\mathrm{Mg}$ and $\mathrm{Al}$ were considered in the first sublattice. SQS approach can thus be used to simulate the random mixing in the first sublattice. Fig. 8 depicts the crystal structure of the SQS-48 structures in their ideal, unrelaxed forms for laves $\mathrm{C} 36$ phase $\left(\mathrm{Mg}_{0.5}, \mathrm{Al} \mathrm{l}_{0.5}\right)_{2} \mathrm{Ca}[63]$.

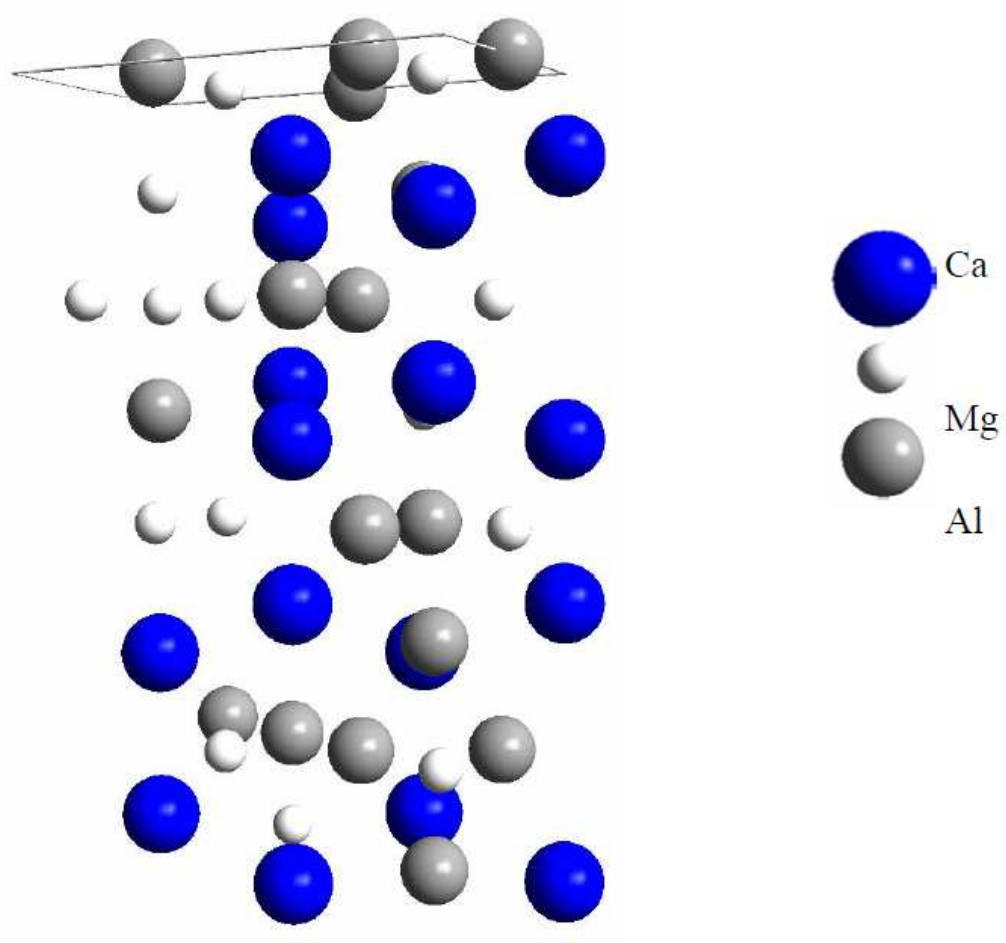

Fig. 8. Crystal structure of the SQS-48 structures in their ideal, unrelaxed forms for laves C36 phase $\left(\mathrm{Mg}_{0.5}, \mathrm{Al}_{0.5}\right)_{2} \mathrm{Ca}[63]$.

The first-principles calculation from SQS coupled with the results from one unit cell and supercell provided us the enthalpy of formation information of the three laves phases: C15, C14, and $\mathrm{C} 36$ in the $\mathrm{A} 12 \mathrm{Ca}-\mathrm{Mg} 2 \mathrm{Ca}$ pseudo-binary system. This was useful for obtaining the interaction parameters in the first sublattice for these three laves phases in $\mathrm{Mg}$-Al-Ca ternary thermodynamic database, which has been used in CALPHAD modeling of the Mg-Al-Ca system.

\subsection{Mobility Database Development}

While the thermodynamic characteristics and equilibrium phase diagrams for most material systems are reasonably well understood $[45,61]$, the diffusion behavior and phase transformation kinetics of many materials is not yet established. First-principles calculations have been explored to generate useful diffusivity data [64-69], however, there is a general scarcity of experimental diffusion data for many materials systems. Diffusion multiple technique $[70,71]$ can be used to generate plenty of diffusion data to fill this gap. A diffusion multiple is an assembly of several metal blocks arranged in a pre-designed geometry to allow many diffusion couples and triples to be assembled in a single sample. This section presents an ongoing effort in developing a mobility database for magnesium alloys. 
To study major magnesium alloy systems, diffusion multiples provide large amounts of binary diffusion profiles for nine binary systems (Mg-Al, Mg-Zn, Mg-Sn, Mg-Ca, Mg-Sr, Mg-Mn, Al$\mathrm{Zn}, \mathrm{Al}-\mathrm{Mn}$, and Mn-Zn) as input to diffusivity extraction. Fig. 9 shows an example of a Mg-Mn diffusion multiple heat-treated at $600^{\circ} \mathrm{C}$ for 48 hours. No intermetallics layer is observed and the concentration profile is measured across the Mg-Mn interface using EPMA (electron probe micro-analysis). By using the forward simulation method [71], the interdiffusion coefficients are extracted, as shown in Fig. 10. This is thought to be the first time that the interdiffusion coefficients of the hcp ( $\mathrm{Mg}$ ) phase of an Mg-Mn system are reported. Results clearly show that the forward simulation method can be used to extract impurity diffusion coefficients, whereas the Sauer-Freise method [72] shows wide scatters of data especially near pure Mg.

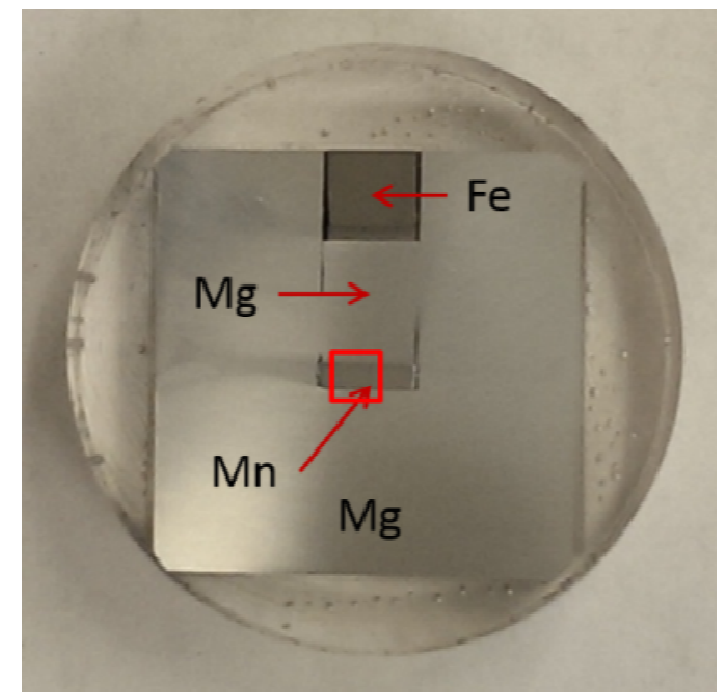

Fig. 9. Mg-Mn diffusion multiple.

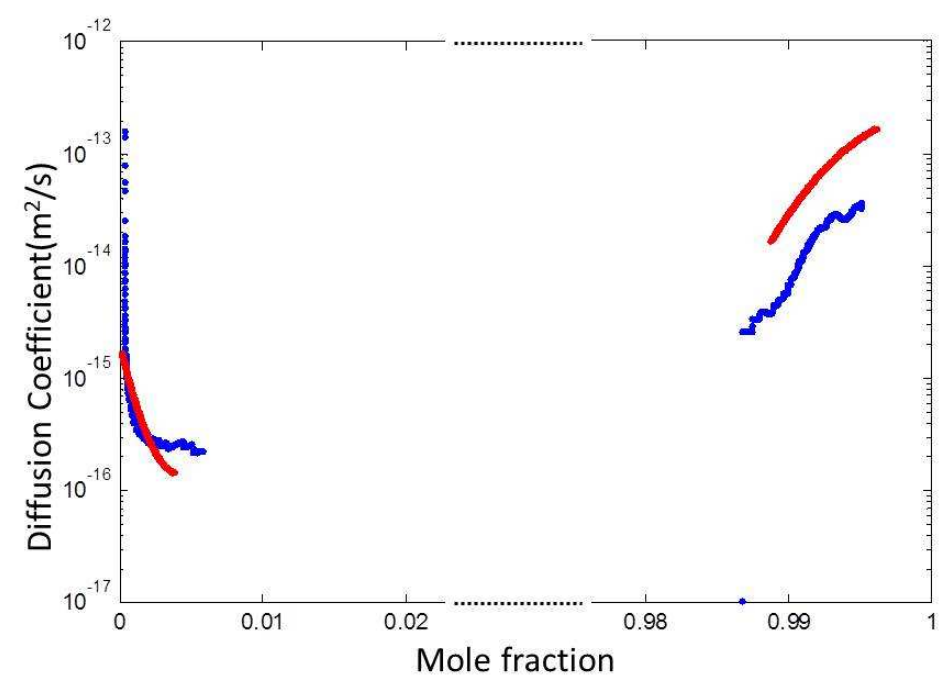

Fig. 10. Comparison of the interdiffusion coefficients obtained from the forward simulation [71] (red lines) with those obtained by the Sauer-Freise method (blue lines) [72]. 
A preliminary atomic mobility database of $\mathrm{Mg}$ alloys of the $\mathrm{Mg}-\mathrm{Al}-\mathrm{Zn}-\mathrm{Mn}-\mathrm{Sn}-\mathrm{Ca}-\mathrm{Sr}$ system is established based on assessment of diffusion data in the literature using the CALPHAD approach. The self-diffusion, impurity diffusion, and interdiffusion coefficients are input to generate the atomic mobility. Empirical methods for estimating the self-diffusion and impurity diffusion coefficients are used to obtain the unavailable data. Most of the literature data are on the diffusion of the $\mathrm{Mg}$ - $\mathrm{Al}$ binary system below $420^{\circ} \mathrm{C}$. Impurity diffusion coefficients of $\mathrm{Zn}$ and $\mathrm{Sn}$ in hcp (Mg) are reported. For $\mathrm{Mn}, \mathrm{Ca}$, and $\mathrm{Sr}$, no experimental data exist yet. Because Al, $\mathrm{Mn}, \mathrm{Ca}, \mathrm{Sn}$, and $\mathrm{Sr}$ do not have a stable hcp structure, the related atomic mobility parameters are estimated using empirical methods. Due to the scarcity of literature data, this preliminary database is still at its early stage and will be improved with ongoing diffusion experiments. Fig. 11 shows the calculated interdiffusion coefficients in the $\mathrm{Mg}$ rich region of the $\mathrm{Mg}$ - $\mathrm{Al}$ system along with experimental data. It clearly demonstrates the need for more diffusion experiments to clarify the discrepancy.

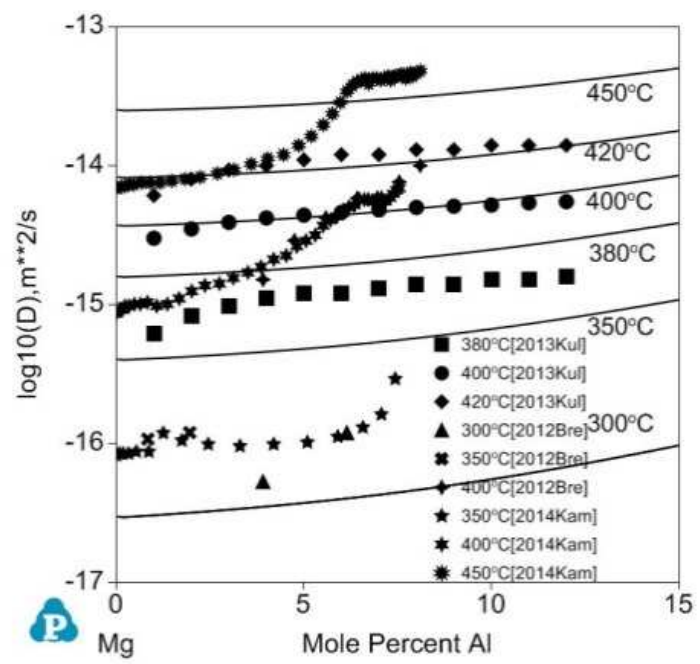

Fig. 11. Calculated interdiffusion coefficients in the $\mathrm{Mg}$ rich region of $\mathrm{Mg}$-Al system along with the experimental data [73-75].

\subsection{Microstructure Simulation}

Microstructure simulation is an important link in the ICME chain of materials design and development. Phase-field simulation based on thermodynamic driving force and ordering potential is considered a powerful tool for modeling the morphology evolution of precipitates in two-dimensional (2D) and three-dimensional (3D) space. In addition, it facilitates the understanding of the effects of various physical factors, such as interface anisotropy and elastic strain energy, on controlling the morphological evolution of precipitates. For example, Li et al. used 2D phase-field method to analyze the effect of elastic strain energy on the precipitation of $\theta^{\prime}$ phase in $\mathrm{Al}-\mathrm{Cu}$ alloy and morphological evolution of $\mathrm{Ti}_{11} \mathrm{Ni}_{14}$ precipitates in $\mathrm{Ti}-\mathrm{Ni}$ alloys under an applied stress [76, 77]. Similarly, Vaithyanathan et al. [78, 79] studied the coarsening kinetics of $\delta^{\prime}-\mathrm{Al}_{3} \mathrm{Li}$ precipitates by using 2D and 3D phase-field simulation. Moreover, they performed 2D multiscale modeling of $\theta^{\prime}$ precipitation in Al-Cu binary alloys using phase-field method and analyzed the effects of interface anisotropy and elastic strain energy on the precipitation. Zhu et 
al. [80] investigated the coarsening kinetics of $\gamma^{\prime}$ precipitates in binary Ni-Al alloy by using 3D phase-field model. Wen et al. [81] simulated the lamellar structure formation of $\gamma$ phase in Ti-Al alloys using 3D phase-field model. More recently, Shi et al. analyzed the equilibrium shape and variant selection of $\alpha$ precipitates in Ti alloys by using the 3D model [82, 83]. Furthermore, for modeling the martensitic transformation, 2D or 3D phase-field simulations are being widely used for analyzing the effects of elastic field, external load, plasticity, and dilatation in single and polycrystalline materials and ceramic materials [84-89].

A 3D phase-field model has been developed to simulate the single $\beta-\mathrm{Mg}_{17} \mathrm{Al}_{12}$ phase precipitation in $\mathrm{Mg}$-Al based alloys, considering the synergistic effects of elastic strain energy, anisotropy of interfacial energy, and anisotropy of interface mobility coefficient [90, 91]. The morphological evolution has been studied based on the effects of interface anisotropy and elastic strain energy on the morphology of a single $\beta-\mathrm{Mg}_{17} \mathrm{Al}_{12}$ precipitate. The simulated precipitates had lath shapes with lozenge ends, and the precipitate variants were parallel on the prism plane and oriented in directions with an angular interval of $60^{\circ}$ on basal plane (Fig. 12). This morphology characteristic is in good agreement with 2D TEM and 3D AFM surface profile observations (Fig. 13).

The distribution of elastic interaction energy near a pre-existing precipitate was calculated by 3D phase field simulation. The results show that the anisotropic elastic interaction can exert a significant effect on the location of subsequent nucleation and promote the formation of the new nucleus near the lozenge ends of the pre-existing precipitate, which are in good agreement with the experimental observations. According to the case studies using the developed 3D phase-field model, different combinations of interface anisotropy and elastic strain energy have an obvious effect on the thickness of $\beta-\mathrm{Mg}_{17} \mathrm{Al}_{12}$ precipitate. Therefore, one possible strategy to increase the thickness, and thereby strengthen the alloy, is to make the interfacial energy equal or as approaching or isotropic as possible. Such an approach is expected to improve the alloy design in Mg-Al-based alloys.

\subsection{Precipitation Simulation}

The classic KWN (Kampmann-Wagner-numerical) precipitation model [92] implemented in the PanPrecipitation module of the Pandat software is used to simulate the precipitation of magnesium alloys during the aging process. This model features the capability of simulating nucleation, growth, and coarsening simultaneously. The PanMagnesium thermodynamic database and the preliminary atomic mobility database are used to generate driving force, phase equilibria, and diffusivity for quantitative simulation.

Coupling to the PanMagnesium thermodynamic database and the preliminary atomic mobility database described above, the precipitation of $\mathrm{Mg}_{2} \mathrm{Sn}$ at $200^{\circ} \mathrm{C}$ in two supersaturated $\mathrm{Mg}-\mathrm{Sn}$ alloys is simulated. The shape of the $\mathrm{Mg}_{2} \mathrm{Sn}$ precipitate is not spherical according to experimental observations [93]. By assuming a shape-preserved growth, the precipitate's shape could be treated as a sphere. The conversion method described by Zhang, et al. [94], is used to calculate the equivalent particle size. Fig. 14(a) shows that the calculated number density for the two Mg-Sn alloys is in agreement with the experimental data. Fig. 14(b) shows the predicted radius for $\mathrm{Mg}-1.9$ at.\% $\mathrm{Sn}$ alloy at 240 hours is $128 \mathrm{~nm}$, which is consistent with the 
experimental value of $112 \mathrm{~nm}$. However, for the $\mathrm{Mg}-1.3$ at.\% $\mathrm{Sn}$ alloy, the simulated radius at 1000 hours is $160 \mathrm{~nm}$, which is lower than the experimental value of $197 \mathrm{~nm}$, but still within the experimental error range. Fig. 14(c) indicates that the precipitation contribution to the yield strength increases while the solution contribution decreases during $\mathrm{Mg}_{2} \mathrm{Sn}$ precipitation in the microstructure. The predicted hardness evolution is consistent with the experimental data in Fig. 14(d) and (e).
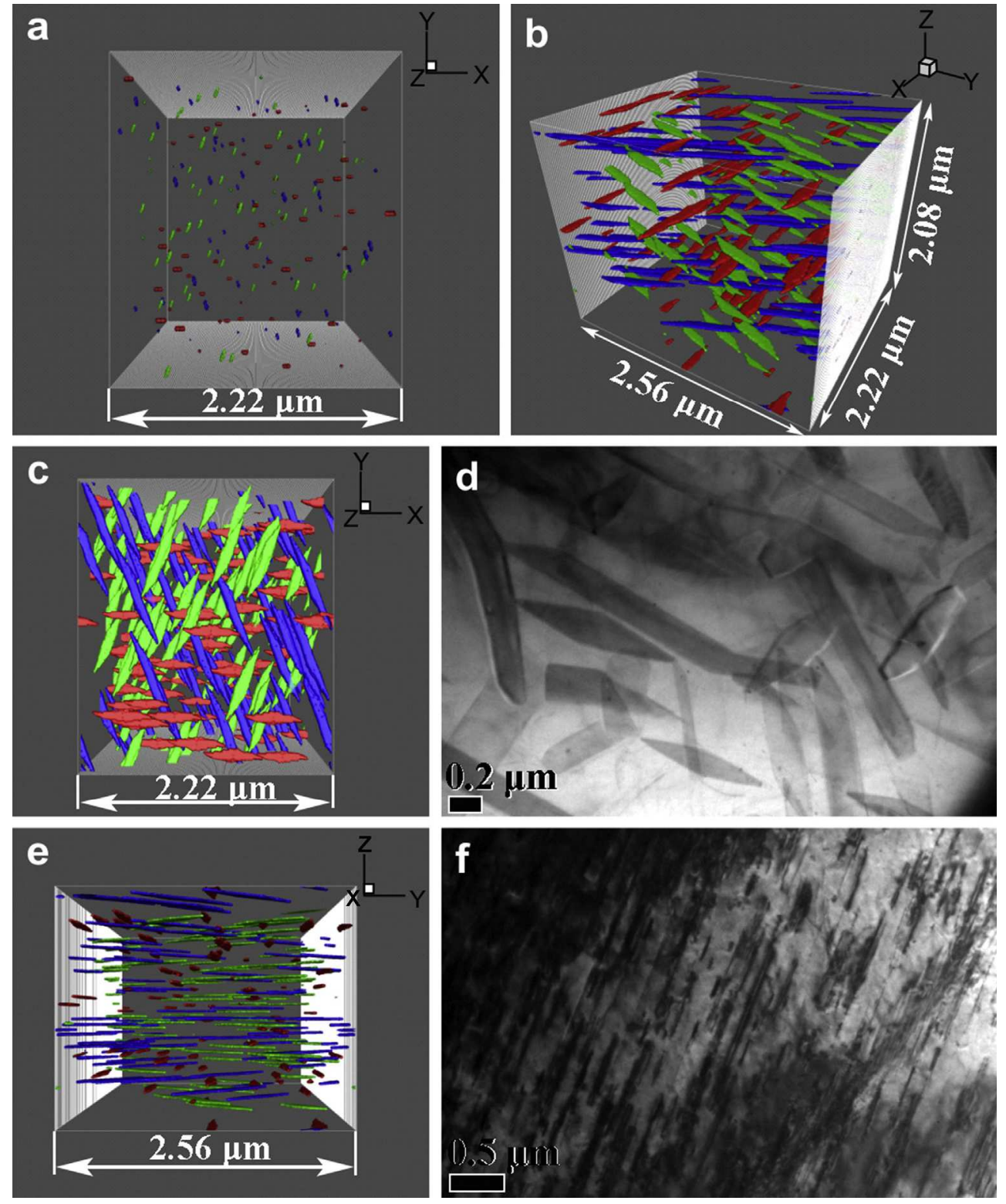

Fig. 12. Simulations and TEM observations of multi-variant precipitation. (a) Simulation results in the $x y$ plane, i.e., (0001) plane of the matrix, $t=0.25 \mathrm{~h}$. (b) Simulation results in three dimensions, $t=2 \mathrm{~h}$. (c) Simulation results in the $x y$ plane, $t=2 \mathrm{~h}$. (d) TEM image of the precipitates in the basal plane for AZ91 aged at $573.15 \mathrm{~K}$ for $2 \mathrm{~h}$. (e) Simulation results in the $x y$ plane, i.e., the prism plane, $t=2 \mathrm{~h}$. (f) TEM image of the precipitates in the prism plane for AZ91 aged at $573.15 \mathrm{~K}$ for $2 \mathrm{~h}$. The size of the computational domain is $2.22 \times 2.56 \times 2.08 \mu \mathrm{m}^{3}$ [90]. 

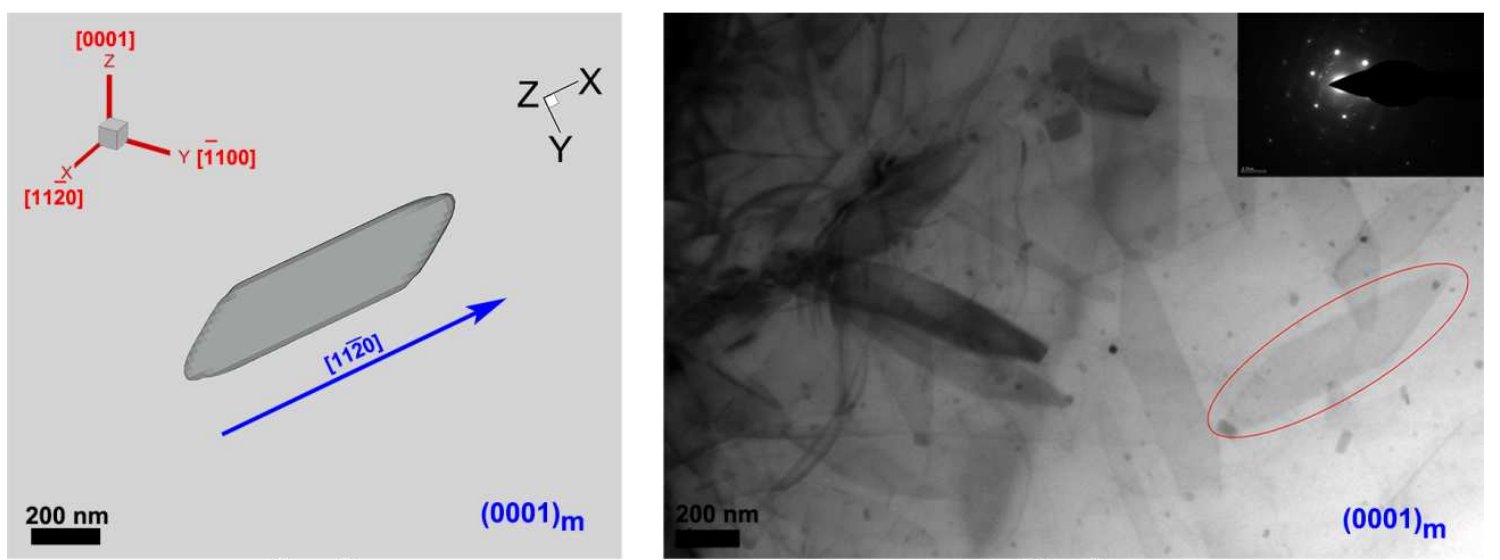

(a)
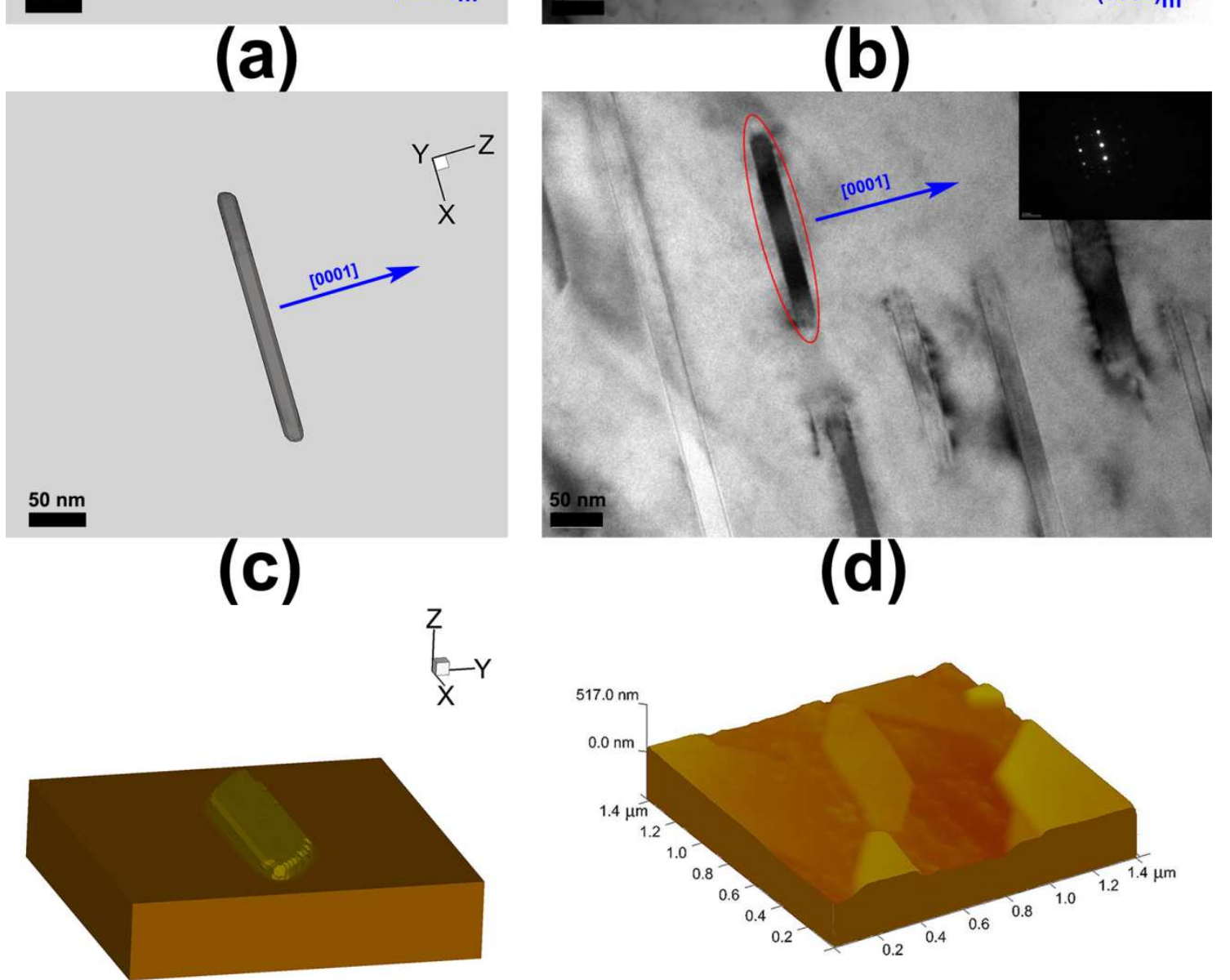

(e)

(f)

Fig. 13. Comparison of the morphology of a single $\beta-\mathrm{Mg}_{17} \mathrm{Al}_{12}$ precipitate obtained by simulations and experimental observations in a $\mathrm{Mg}$ - $\mathrm{Al}$ alloy aged at $573 \mathrm{~K}\left(300^{\circ} \mathrm{C}\right)$ : (a) and (c) the simulation results of precipitate morphology projected in 2D $x y$ and $x z$ planes (the basal and prism planes), respectively; (e) the simulation morphology of precipitate in $3 \mathrm{D}$; (b) and (d) the TEM images of precipitate lying in basal and prism planes, respectively, for AZ91 alloy aged at $573 \mathrm{~K}\left(300^{\circ} \mathrm{C}\right)$ for $2 \mathrm{~h}$; (f) $3 \mathrm{D}$ surface plot of precipitate obtained by $\mathrm{AFM}$ in its topographic modes for AZ91 aged at $573 \mathrm{~K}\left(300^{\circ} \mathrm{C}\right)$ for $2 \mathrm{~h}[91]$. 


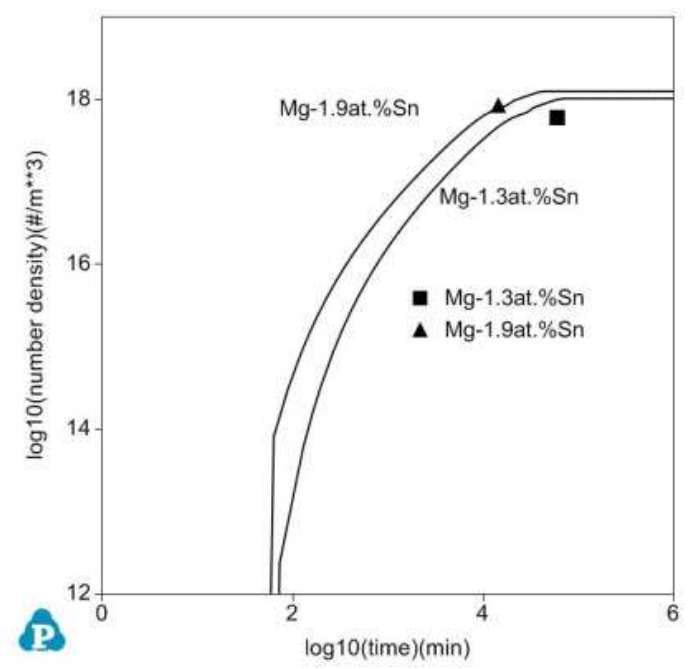

(a)

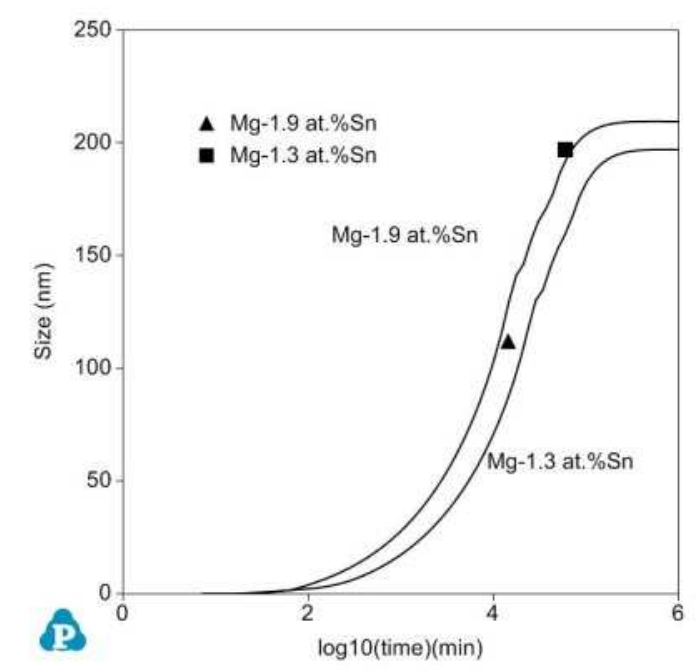

(b)

Fig. 14(a). Predicted number density of $\mathrm{Mg}_{2} \mathrm{Sn} \quad$ Fig. 14(b). Predicted radius of $\mathrm{Mg}_{2} \mathrm{Sn}$ precipitate in $\mathrm{Mg}-1.3$ at.\% $\mathrm{Sn}$ and $\mathrm{Mg}-1.9$ at.\% alloys along with the experimental data [77]. precipitate in $\mathrm{Mg}-1.3$ at.\% Sn and $\mathrm{Mg}-1.9$ at.\% alloys along with the experimental data [77].

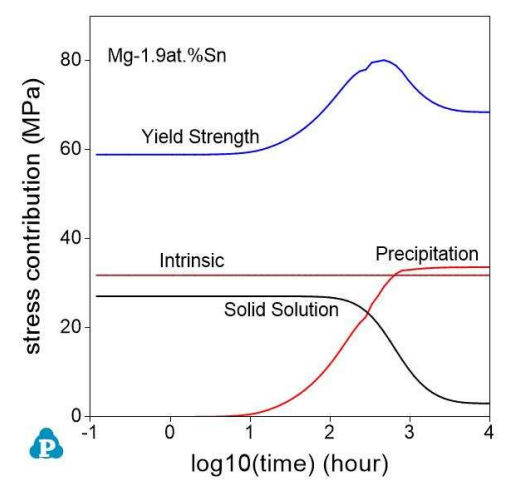

(c)

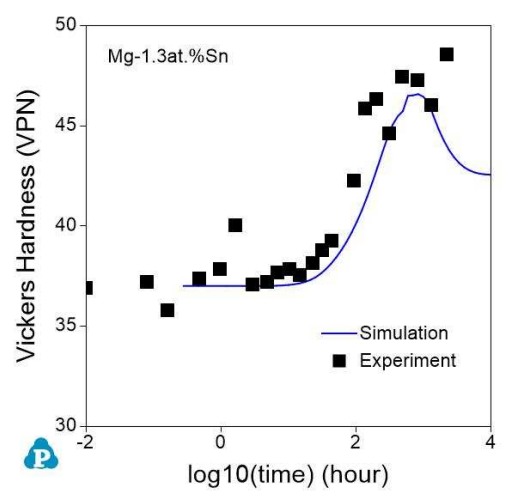

(d)

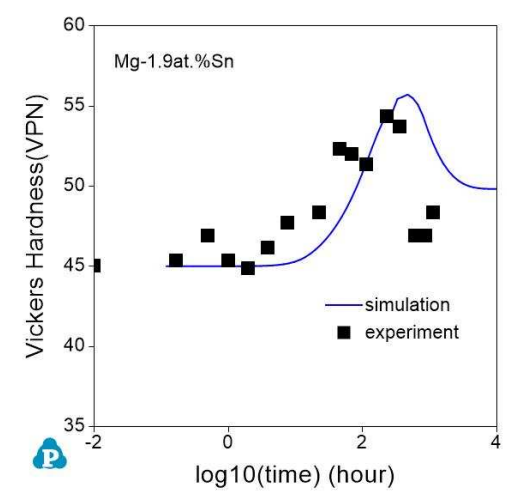

(e)

Fig. 14(c). Predicted yield Fig. 14 (d, e). Predicted hardness evolution with the strength contributions for $\mathrm{Mg}$ - experimental data [77]: (d) $\mathrm{Mg}-1.3$ at. $\% \mathrm{Sn}$; and (e) $\mathrm{Mg}$ 1.9 at.\% Sn. 1.9 at.\% Sn.

\section{Summary and Future Outlook}

This paper reviews three major approaches for materials design and development in the last 50 years: classical thermodynamics, CALPHAD and the emerging ICME approaches. While classical thermodynamics are still useful in solving specific "isolated" phase transformation problems, providing qualitative guidance for material development; CALPHAD, based computational thermodynamics, is becoming a cornerstone in the new ICME approach where new materials and products can be designed and optimized using simulation tools (not trial-and- 
error) to meet specific system design goals $[95,96]$. ICME can unite materials, manufacturing and system design into a holistic computational framework in the development of new materials and manufacturing processes as shown in Fig. 15, where system/product design models and materials models (CALPHAD-based) can be linked to manufacturing process models to predict location-specific microstructures and location-specific properties, leading to the most efficient engineering products.

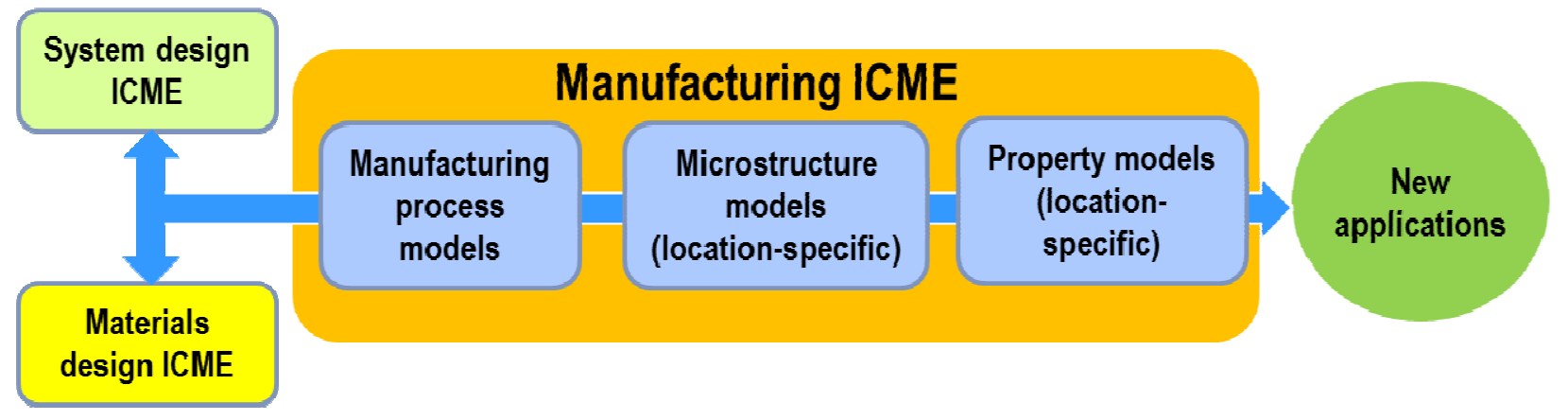

Fig. 15. Integrated computational materials engineering (ICME) flow chart for new application development.

There are still significant challenges for this ICME flow chart to work smoothly and efficiently for the materials and manufacturing communities. Some of them are summarized as follows:

1) Mobility databases and kinetics models. While the thermodynamic characteristics and equilibrium phase diagrams for many material systems are reasonably well understood, the phase transformation and diffusion behaviors of these materials has been explored to a far lesser extent. High-throughput diffusion multiple technique and improved models for extracting diffusivity data, assisted by first-principle calculations, can be used to fill this gap. On a broader scope, several national MGI efforts are ongoing in the US. For example, National Institute of Standards and Technology (NIST) is creating repositories of materials data and models that result from research funded by the DOE-EERE (Office of Energy Efficiency and Renewable Energy of the Department of Energy) program in lightweight automotive materials.

2) Microstructure simulation. Despite the significant progress of many simulation techniques for microstructure evolution during materials processing, such as phase-field [97], cellular automata [98] and Monte Carlo [99], mesoscale 3D microstructure models are often too complex and time-consuming for ICME implementation in industry. Research opportunities exist in establishing practical 3D microstructure models to predict the mechanical and physical performance of new materials/components early in the design stages.

3) Model integration. Current material modeling is generally fragmented with commercial software and research codes focusing on solving specific problems, but not fully integrated for ICME implementation. Such integration would require interdisciplinary 
(e.g., computer science and software engineering) and industry/academia collaboration in multi-scale simulation resolving fundamental numerical issues in materials and process models in different length scales; and software integration establishing interfaces and automatic (vs. current "manual") data transfer across the ICME modeling chain.

These challenges also present great research opportunities for the international materials and manufacturing communities. In the United States, several national MGI/ICME projects [100104] have been launched in the last few years to address fundamental challenges in computational design and development of structural and functional materials. There are also significant efforts in Europe [105-107] and China [108] in the MGI/ICME domain to advance databases, models and methodologies for accelerated development of materials. The future of "Materials by Design" [1] is increasingly likely with the rapidly evolving MGI/ICME developments around the world.

\section{Acknowledgements}

The author acknowledges the financial support from the National Science Foundation (CMMI1432688 and DMR1005762), the Department of Energy (DE-EE0005753 and DE-EE0006450), and the United States Automotive Materials Partnership (a consortium of GM, Ford and Chrysler). The author is grateful to General Motors for many years of support during his tenure at GM R\&D (1998-2013) and continued collaboration with Drs. Anil Sachdev, Bob Powell, Jon Carter and Raj Mishra. The author would like to thank Profs. J.-C. Zhao, Glenn Daehn, Jerry Brevick, Yunzhi Wang, and many students and research fellows (particularly Weihua Sun, Wei Zhong, Andrew Klarner, Emre Cinkilic, Scott Sutton, Zhi Liang, Yan Lu, Xiaoying Shi) at The Ohio State University. The author appreciates the fruitful collaborations and discussions with University of Windsor (Prof. Bill Youdelis), Pennsylvania State University (Profs. Z.K. Liu and L.Q. Chen), University of Wisconsin-Madison (the late Prof. Austin Chang), CompuTherm (Drs. Fan Zhang, Chuan Zhang, Shuanglin Chen and Weisheng Cao), Tsinghua University (Prof. Baicheng Liu's group), Shanghai Jiaotong University (Prof. Wenjiang Ding's group), Clausthal University of Technology (Prof. Rainer Schmid-Fetzer), Northwestern University (Prof. Greg Olson), and University of Michigan (Profs. John Allison and Alan Taub).

\section{References}

1. G.B. Olson, Science, 2000, 288, (12), 993.

2. G.B. Olson, Acta Mater Diamond Jubilee Issue, 2013, 61, 771.

3. C.J. Kuehmann, G.B. Olson, in Models, Databases and Simulation Tools Needed for the Realization of Integrated Computational Materials Engineering, eds. S. Arnold \& T. Wong, ASM, 2011.

4. J.-C. Zhao, M.F. Henry, Advanced Engineering Materials, 4, (7), 2002, 501.

5. A.A. Luo, R.K. Mishra, B.R. Powell, A.K. Sachdev, Materials Science Forum, 2012, 706709, 69.

6. A.A. Luo, B.R. Powell, A.K. Sachdev, Intermetallics, 2012, 24, 22. 
7. A.A. Luo, in Proceedings of the 2nd World Congress on Integrated Computational Materials Engineering, M. Li et al, eds., The Minerals, Metals \& Materials Society (TMS), Warrendale, PA, USA, 2013, 3.

8. T.M. Pollock, J.E. Allison, D.G. Backman, M.C. Boyce, M. Gersh, E.A. Holm, R. LeSar, M. Long, A.C. Powell, IV, J.J. Schirra, D.D. Whitis, C. Woodward, "Integrated Computational Materials Engineering: A Transformational Discipline for Improved Competitiveness and National Security", The National Academies Press, 500 Fifth Street, N.W. Washington, DC 20001, 2008.

9. "Materials Genome Initiative", http://www.whitehouse.gov/mgi.

10. D. Apelian, A. Alleyne, C. Handwerker, D. Hopkins, J. Isaacs, G. Olson, R. Vaidyanathan, S. Wolf, "Accelerating Technology Transition: Bridging the Valley of Death for Materials and Processes in Defense Systems", The National Academies Press, 500 Fifth Street, N.W. Washington, DC 20001, 2004.

11. C. Brinson, J. Allison, J. Chen, D. Clarke, B. Cowles, G. Gray, E. Greene, W. Harris, M. Mehta, G. Olson, C. Saff, D. Tenney, F. Zok, "Applications of Lightweighting Technology to Military Vehicles, Vessels and Aircraft", The National Academies Press, 500 Fifth Street, N.W. Washington, DC 20001, 2012.

12. I. Polmear, Light Alloys: From Traditional Alloys to Nanocrystals, Elsevier, 2005.

13. A.I. Taub, P.E. Krajewski, A.A. Luo, and J.N. Owens, JOM, 2007, 59, (2), 48.

14. M. Volmer and A. Weber, Z. Phys. Chem., 1926, 119, 227.

15. R. Becker and W. Doring, Ann. Phys., 1935, 24, 719.

16. D. Turnbull and J.C. Fisher, J. Chem Phys., 1949, 17, 71.

17. J.W. Christian, The Theory of Transformation in Metals and Alloys, Pergamon Press, Oxford, 1964, 537.

18. W.V. Youdelis, Met. Sci., 1975, 9, 464.

19. W.V. Youdelis, Met. Sci., 1979, 13, 540.

20. W.V. Youdelis and C.-S. Yang, Met. Sci., 1982, 16, 275.

21. S.P. Iyer and W.V. Youdelis, Aluminum, 1977, 53, 252.

22. W.V. Youdelis and C.-S. Yang, Met. Sci., 1980, 14, 500.

23. A. Ramon and K. Schubert, Z. Metallkd., 1965, 65, 44.

24. G.W. Delamore and R.W. Smith, Metall. Trans., 1971, 2, 1733.

25. W.V. Youdelis and O. Kwon, Met. Sci., 1983, 17, 379.

26. W.V. Youdelis and O. Kwon, Met. Sci., 1983, 17, 385.

27. W.V. Youdelis and J. Karov, Mat. Sci. Forum, 1987, 13/14, 483.

28. J. Karov, Ph.D. Thesis, University of Windsor, Windsor, Ontario, 1985.

29. J. Karov and W.V. Youdelis, Mat. Sci. Technol., 1987, 3, 394.

30. J. Karov and W.V. Youdelis, Mat. Sci. Technol., 1987, 3, 1.

31. T. Xiao and W.V. Youdelis, Mat. Sci. Technol., 1989, 5, 991.

32. W. Fang, Ph.D. Thesis, University of Windsor, Windsor, Ontario, 1992.

33. F.R.N. Nabarro, Proc. Roy. Soc., 1940, A175, 519.

34. J.D. Eshelby, Proc. Roy. Soc., 1957, A241, 376.

35. J.K. Lee, D.M. Barbett and H.I. Aaronson, Metall. Trans. A, 1977, 8A, 963.

36. E.J. Lavernia and N.J. Grant, J. Mater. Sci., 1987, 23, 1521.

37. P.J. Gregson and H.M. Flower, Acta Metall., 1985, 33, 527.

38. A. Luo, W.V. Youdelis, Metall. Trans. A, 1993, 24, 95.

39. A.A. Luo, Ph.D. Thesis, University of Windsor, Windsor, Ontario, 1992.

40. J.L. Murray, Bulletin of Alloy Phase Diagrams, 1989, 10, (4), 351. 
41. J.L. Murray and D.J. Kahan, Bulletin of Alloy Phase Diagrams, 1983, 4, (4), 50.

42. R.C. Dorward, Metall. Trans. A, 1988, 19A, 1631.

43. J.M. Stuve and M.J. Ferrante, U.S. Dept. of the Interior, Bureau of Mines Report R17834, 1974.

44. J. White, W.S. Miller, I.G. Palmer, R. Davis, and T.S. Saini, in Aluminum-Lithium III, Proc. 3rd Int. A1-Li Conf., P.J. Gregson and S.J. Harris, eds., Institute of Metals, London, 1986, 530.

45. L. Kaufman and H. Bernstein, Computer Calculation of Phase Diagram, Academic Press Inc., New York, 1970.

46. Y.A. Chang, S. Chen, F. Zhang, X. Yan, F. Xie, R. Schmid-Fetzer, W.A. Oates, Prog. Mater Sci., 2004, 49, 313.

47. Y.A. Chang, Y. Yang, in Methods for phase diagram determination, Zhao J-C, editor, Oxford, UK: Elsevier, Ltd.; 2007, 273.

48. http://www.thermocalc.com/

49. http://www.factsage.com/

50. http://www.computherm.com/

51. W.E. Mercer II, SAE Technical Paper 900788, Society of Automotive Engineers, Warrendale, PA, USA, 1990.

52. P. Bakke and H. Westengen, in Magnesium Technology 2005, TMS, 291.

53. A.A. Luo, in Proc. of the 2nd World Congress on Integrated Computational Materials Engineering, M. Li et al, eds., The Minerals, Metals \& Materials Society (TMS), Warrendale, PA, USA, 2013, 3.

54. J. Aragones, K. Goundan, S. Kolp, R. Osborne, L. Ouimet, W. Pinch, SAE Technical Paper No. 2005-01-0340, SAE International, Warrendale, PA, USA, 2005.

55. A.A. Luo, M.P. Balogh, B.R. Powell, Metall. Mater. Trans. A, 2002, 33, 567.

56. A. Suzuki, N.D. Saddock, J.W. Jones, T.M. Pollock, Acta Materialia, 2005, 53, 2823.

57. A.A. Luo, B.R. Powell, A.K. Sachdev, Intermetallics, 2012, 24, 22.

58. J.A. Catterall, R.J. Pleasance, J. Inst. Metals, 1957-58, 86, 189.

59. R. Ninomiya, T. Ojiro, K. Kubota, Acta Metall. Mater., 1995, 43, 669.

60. M. Liu, Q. Wang, Z. Liu, G. Yuan, G. Wu, Y. Zhu, W.J. Ding, Mater. Sci. Lett., 2002, 21, 1281.

61. Z.K. Liu, J. Phase Equilib. Diff., 2009, 30, (5), 517.

62. A.A. Luo, W. Sun, W. Zhong, J.C. Zhao, Advanced Materials and Processes, 2015, 173, (1), 26.

63. Y. Zhong, A.A. Luo, J.O. Sofo and Z-K Liu, Mat. Sci. Forum, 2005, 488-489, 169.

64. S. Ganeshan, L.G. Hector and Z.K. Liu, Acta Mater., 2011, 59, 3214.

65. S. Ganeshan, L.G. Hector and Z.K. Liu, Comput. Mater. Sci., 2010, 50, 301.

66. M. Mantina, Y. Wang, L.Q. Chen, Z.K. Liu and C. Wolverton, Acta Mater., 2009, 57, 4102.

67. M. Mantina, S.L. Shang, Y. Wang, L.Q. Chen and Z.K. Liu, Phys. Rev. B, 2009, 80, 184111.

68. M. Mantina, L.Q. Chen and Z.K. Liu, Defect and Diffusion Forum, 2009, 294, 1.

69. M. Mantina, Y. Wang, R. Arroyave, L.Q. Chen, Z.K. Liu and C. Wolverton, Phys. Rev. Lett., 2008, 100, 215901.

70. J. C. Zhao, Prog. Mater. Sci., 51, 2006, 557.

71. Q. Zhang, J.-C. Zhao, Intermetallics, 2013, 34, 132.

72. F. Sauer, V.Z. Freise, Elektrochem., 1962, 66, 353. 
73. C. Kammerer, N. Kulkarni, R. Warmack, K. Perry, I. Belova, G. Murch, Y. Sohn, in Magnesium Technology 2014, Eds., M. Alderman, M.V. Manuel, N. Hort, N.R. Neelameggham, TMS, 2014, 505.

74. S. Brennan, K. Bermudez, N.S. Kulkarni, Y. Sohn, Metall. Mater. Trans. A.2012, 43, 4043.

75. K.N. Kulkarni, A.A Luo, J. Phase Equilib. Diff., 2013, 34, (2), 104.

76. D.Y. Li and L.Q. Chen, Acta Metall. Mater., 1998, 46, 2573.

77. D.Y. Li and L.Q. Chen, Acta Metall. Mater., 1998, 46, 639.

78. V. Vaithyanathan and L.Q. Chen, Scripta Mater., 2000, 42, 967.

79. V. Vaithyanathan, C. Wolverton, L.Q. Chen, Phys. Rev. Lett., 2002, 88, 125503.

80. J.Z. Zhu, T. Wang, A.J. Ardell, S.H. Zhou, Z.K. Liu, L.Q. Chen, Acta Mater., 2004, 52, 2837.

81. Y.H. Wen, L.Q. Chen, P.M. Hazzledine, Y. Wang, Acta Mater., 2001, 49, 2341.

82. R. Shi, N. Ma, Y. Wang, Acta Mater., 2012, 60, 4172.

83. R. Shi and Y. Wang, Acta Mater., 2013, 61, 6006.

84. W. Zhang, Y.M. Jin, A.G. Khachaturyan, Acta Mater., 2007, 55, 565.

85. H.K. Yeddu, A. Malik, J. Agren, G. Amberg, A. Borgenstam, Acta Mater., 2012, 60, 1538.

86. A. Malik, H.K. Yeddu, G. Amberg, A. Borgenstam, J. Agren, Mater. Sci. Eng. A, 2012, 556, 221.

87. H.K. Yeddu, A. Borgenstam, J. Agren, Acta Mater., 2013, 61, 2595.

88. A. Malik, G. Amberg, A. Borgenstam, J. Agren, Acta Mater., 2013, 61, 7868.

89. M. Mamivand, M.A. Zaeem, H.E. Kadiri, L.Q. Chen, Acta Mater., 2013, 61, 5223.

90. Z. Han, G. Han, A.A. Luo, B. Liu, Computational Materials Science, 2015, 101, 248.

91. G. Han, Z. Han, A.A. Luo, B. Liu, Metall. and Mater. Trans. A, 2015, 46, (2), 948.

92. R. Kampmann, R. Wagner, in Decomposition of Alloys: Proceedings of the $2^{\text {nd }}$ ActaScriptaMetallurgica Conference, P. Haasen, V. Gerold, R. Wagner, Eds. Pergamon Press, 1983, 91.

93. C.L. Mendis, C.J. Bettles, M.A. Gibson, S. Gorsse, C.R. Hutchinson, Phil. Mag. Let., 2006, 86(7), 443.

94. C. Zhang, W. Cao, S.L. Chen, J. Zhu, F. Zhang, A.A. Luo, R. Schmid-Fetzer, JOM, 2014, 66, (3), 389.

95. R. Schmid-Fetzer, J. Phase Equilib. Diff., 35, (6), 2014, 735.

96. G.B. Olsona, C.J. Kuehmann, Scripta Materialia, 2014, 70, 25.

97. I. Steinbach, Annu. Rev. Mater. Res., 2013, 43, 89.

98. D. Raabe, Annu. Rev. Mater. Res., 2002, 32, 53.

99. E.A. Holm and C.C. Battaile, JOM, 2001, (9), 20.

100. https://materialsproject.org/

101. www.nanoHUB.org

102. http://www.nist.gov/mml/coe-120313.cfm

103. http://prisms.engin.umich.edu/\#/prisms

104. http://www.ccmd.psu.edu/

105. J. Agren, Metall. Mater. Trans. A, 2012, 43, 3453.

106. J. Hirsch (Ed.), Virtual Fabrication of Aluminum Products, Wiley-VCH, Weinheim, 2006.

107. G. Gottstein (Ed.), Integral Materials Modeling: Towards Physics- Based Through-Process Models, Wiley-VCH, Weinheim, 2007.

108. Chinese Science Bulletin, Special Issue: Materials Genome, 2014, 59, (15). 